26

RFP-922

all 1101

DISSOLUTION OF PLUTONIUM OXIDE

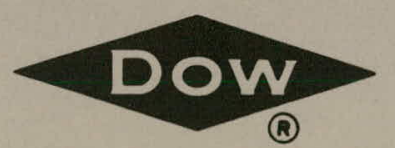

THE DOW CHEMICAL COMPANY

ROCKY FLATS DIVISION

P. O. BOX 888

GOLDEN, COLORADO 80401

U.S. ATOMIC ENERGY COMMISSION

CONTRACT AT(29-1)-1106 


\section{DISCLAIMER}

This report was prepared as an account of work sponsored by an agency of the United States Government. Neither the United States Government nor any agency Thereof, nor any of their employees, makes any warranty, express or implied, or assumes any legal liability or responsibility for the accuracy, completeness, or usefulness of any information, apparatus, product, or process disclosed, or represents that its use would not infringe privately owned rights. Reference herein to any specific commercial product, process, or service by trade name, trademark, manufacturer, or otherwise does not necessarily constitute or imply its endorsement, recommendation, or favoring by the United States Government or any agency thereof. The views and opinions of authors expressed herein do not necessarily state or reflect those of the United States Government or any agency thereof. 


\section{DISCLAIMER}

Portions of this document may be illegible in electronic image products. Images are produced from the best available original document. 


\section{LEGAL NOTICE}

This report was prepared as an account of Government sponsored work. Neither the United States, nor the Commission, nor any person acting on behalf of the Commission:

A. Makes any warranty or representation, expressed or implied, with respect to the accuracy, completeness, or usefulness of the information contained in this report, or that the use of any information, apparatus, method, or process disclosed in this report may not infringe privately owned rights; or

B. Assumes any liabilities with respect to the use of, or for damages resulting from the use of any information, apparatus, method, or process disclosed in this report.

As used in the above, "person acting on behalf of the Commission" includes any employee or contractor of the Commission, or employee of such contractor, to the extent that such employee or contractor of the Commission, or employee of such contractor prepares, disseminates, or provides access to, any information pursuant to his employment or contract with the Commission, or his employment with such contractor.

Printed in the United States of America

Available from

Clearinghouse for Federal Scientific and Technical Information

National Bureau of Standards, U, S. Department of Commerce

Springfield, Virginia 22151

Price: Printed Copy $\$ 3.00$; Microfiche $\$ 0.65$ 


\title{
DISSOLUTION OF PLUTONIUM OXIDE
}

\author{
Garrel F. Molen
}

\section{LEGAL NOTICE}

This report was prepared as an account of Government sponsored work. Neither the United States, nor the Commission, nor any person acting on behalf of the Commission:

A. Makes any warranty or representation, expressed or implied, with respect to the accuracy, completeness, or usefulness of the information contained in this report, or that the use of any informatton, apparatus, meithod, or procese disclosed in this report may not infringe privately owned rights; or

D. Aosumoo any liahilities with respect to the use of, or for damages resulting from the
privately owned right: or D. Aosumoo any liahilities with respect to the use of, or for damages rest.
of any information, apparatus, method, or process disclosed in this report.

(ne of any information, apparatus, method, or process disclosed in this report.

As used in the above. "person acting on behalf of the Commission" includes any em-
ployee or contractor of the Commiseion, or employee of such contractor, to tie extent that f. such employee or contractor of the Commission, or employee of such contractor prepares,

disseminates, or provides accese to, any information pursuant to his employment or contrac

with the Commission, or his employment with such contractor.

$$
-\cdots
$$

\footnotetext{
THE .DOW CHEMICAL COMPANY ROCKY FLATS DIVISION

P. O. BOX 888

GOLDEN, COLORADO 80401

U. S. ATOMIC ENERGY COMMISSION

CONTRACT AT(29-1)-1106
} 
RFP-922 


\section{O N T E N T S}

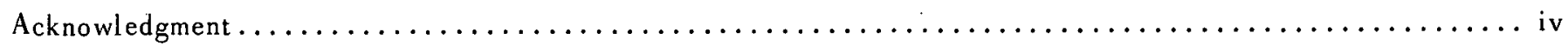

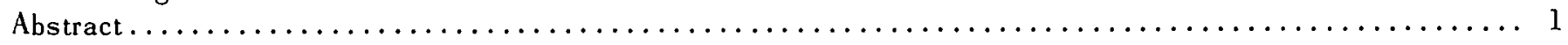

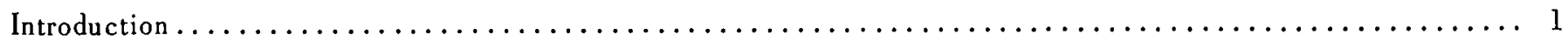

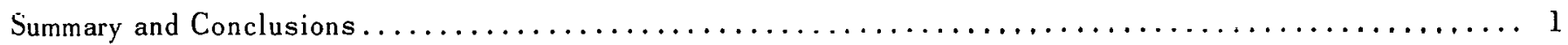

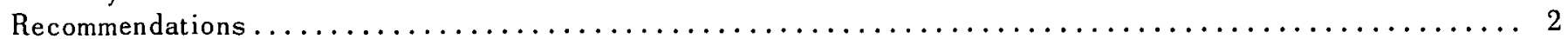

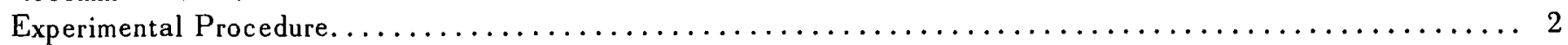

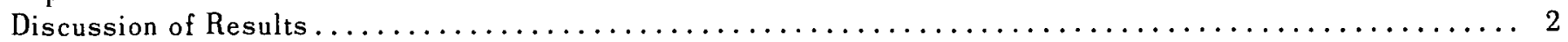

The Nitric Acid-Calcium Fluoride Solvent System . . . . . . . . . . . . . . . . . . . . .

The Effect of the Solid-to-Liquid Ratio on the Dissolution Rate of Plutonium Oxide

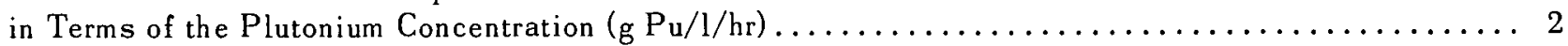

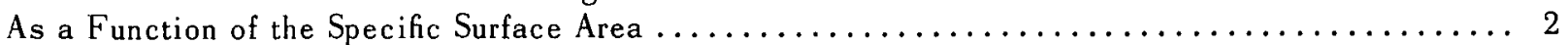

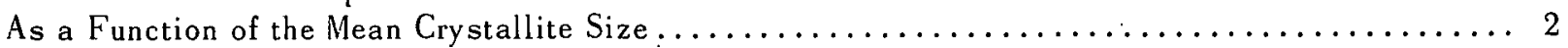

As a Function of the Mean Crystallite Size for a Given Specific Surface Area. .............. 3

As a Function of the Specific Surface Area for a Given Mean Crystallite Size............... 3

The Effect of the Solid-to-Liquid Ratio on the Dissolution Rate of Plutonium Oxide

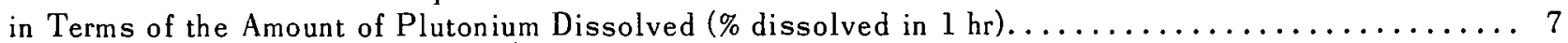

As a Function of the Specific Surface Area . . . . . . . . . . . . . . . . . . . . . . . .

As a Function of the Mean Crystallite Size . . . . . . . . . . . . . . . . . . . . . . . .

As a Function of the Mean Crystallite Size for a Given Specific Surface Area................ 10

As a Function of the Specific Surface Area for a Given Mean Crystallite Size................ 10

The Hydrochloric Acid-Stannous Chloride Solvent System . . . . . . . . . . . . . . . . . . . . 11

The Effect of the Solid-to-Liquid Ratio on the Dissolution Rate of Plutonium Oxide

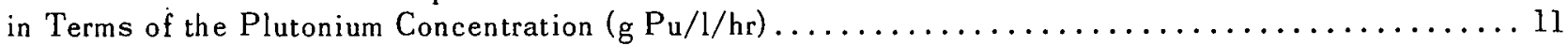

As a Function of the Specific Surface Area . . . . . . . . . . . . . . . . . . . . . . . . .

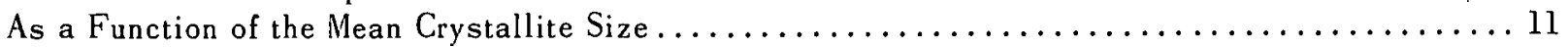

As a Function of the Mean Crystallite Size for a Given Specific Surface Area. . . . . . . . . . . . . 14

As a Function of the Specific Surface Area for a Given Mean Crystallite Size............... 14

The Effect of the Solid-to-Liquid Ratio on the Dissolution Rate of Plutonium Oxide

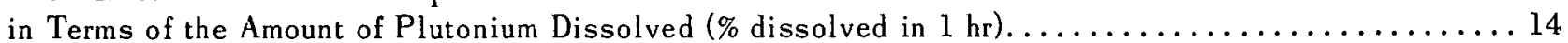

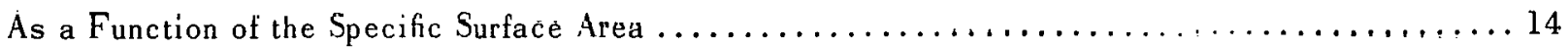

As a Function of the Mean Crystallitc Size ............................. $\ldots$

As a Function of the Mean Crystallite Size for a Given Specific Surface Area. . . . . . . . . . . . 15

As a Function of the Specific Surface Area for a Given Mean Crystallite Size. . . . . . . . . . . 15

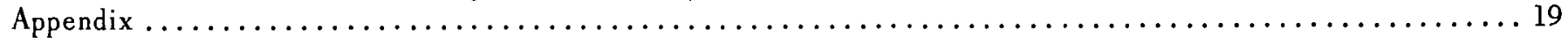




\section{ACKNOWLEDGMENT}

I am indebted to E. J. Tomasi and I. D. Navratil for performing the experimental work. I wish to thank the Plutonium Analytical Laboratory personnel, under the direction of L. F. Grill, for their cooperation in performing the analyses required for this study. 


\title{
Dissolution of Plutonium Oxide
}

\author{
Garrel F. Molen
}

Abstract. The dissolution rate of plutonium oxide as a function of the specific surface area and the mean crystallite size is described. The effect of the solidto-liquid ratio is measured in both a nitric acidcalcium fluoride solvent system and in a hydrochloric acid-stannous chloride solvent system.

\section{INTRODUCTION}

During the foundry and fabrication processes involved in the casting and machining of plutonium metal, scrap metal is generated which can not be reused without purification. At the Rocky Flats Plant the scrap metal is burned and the oxide is dissolved in a nitric acidcalcium fluoride solvent system and the plutonium is recovered and purified from the resulting solution by peroxide precipitation. The peroxide precipitate is calcined, hydrofluorinated to the tetrafuoride, and then reduced to plutonium metal.

When the scrap is burned in air, the temperature at which the scrap is burned is not controlled and varies from $-700^{\circ} \mathrm{C}$ to $-1200^{\circ} \mathrm{C}$. The oxide which results has a plutonium content ranging from $82.4 \%$ to $89.8 \%$ with a specific surface area ${ }^{1}$ ranging from $0.4 \mathrm{~m}^{2} / \mathrm{g}$ to $6.7 \mathrm{~m}^{2} / \mathrm{g}$ and a mean crystallite size ranging from $210 \AA$ to $450 \AA$. The extreme variability in these properties effects the dissolution rate of the oxide. The purpose of this investigation was to measure the effects of these properties on the dissolution rate of the oxide.

The effects of four variables on the dissolution rate of the plutonium oxide were studied. The variables were the specific surface area of the oxide, the mean crystallite size of the oxide, the solid-to-liquid ratio used for dissolving the oxide, and the type of solvent system

\footnotetext{
${ }^{1}$ Specific surface area measurements were made by $x$-ray diffraction techniques.

${ }^{2}$ Mean crystallite size measurements were made by Brunauer, Emmetr and Teller (BET) adsurptiun teilmique.
}

\section{SUMMARY AND CONCLUSIONS}

The effect of the solid-to-liquid ratio on the dissolution rate of plutonium oxide as a function of the specific surface area, the mean crystallite size, the mean crystallite size for a given specific surface area, and the specific surface area for a given mean crystallite size has been determined. Plutonium oxide samples, with varying specific surface area and mean crystallite sizes, were dissolved in both a nitric acidcalcium fluoride solvent system and in a hydrochloric acid-stannous chloride solvent system using three solid-to-liquid ratios. The results were calculated with the plutonium concentration being expressed in grams of plutonium dissolved per liter of solvent, and with the amount of plutonium dissolved being expressed in percent of the total plutonium in the solid.

The results showed that the dissolution rate of the oxide was more dependent on the specific surface area than on the mean crystallite size. In the nitric acid solvent system the plutonium concentration $(\mathrm{g} \mathrm{Pu} / \mathrm{l} / \mathrm{hr})$ increased as the solid-to-liquid ratio increased for a given specific surface area or mean crystallite size. In this same solvent system the amount of plutonium dissolved (\% dissolved in $1 \mathrm{hr}$ ) decreased as the solidto-liquid ratio increased for a given specific surface area or mean crystallite size. In the hydrochloric acid solvent system the plutonium concentration $(\mathrm{g} \mathrm{Pu} / \mathrm{l} / \mathrm{hr})$ increased as the solid-to-liquid ratio increased for a given specific surface area or mean crystallite size. In this same system the amount of plutonium dissolved (\% dissolved in $1 \mathrm{hr}$ ) did not change as the solid-toliquid ratio increased for a given specific surface area or mean crystallite size.

Small increases $(<100 \AA)$ in the mean crystallite size did not significantly decrease the dissolution rate of the oxide; however, larger increases did decrease the dissolution rate. Increases less than $0.8 \mathrm{~m}^{2} / \mathrm{g}$ in the specific surface area did not significantly increase the rate of dissolution except under special circumstances. Increases greater than $0.8 \mathrm{~m}^{2} / \mathrm{g}$ increased the rate of dissolution in all cases.

The rate of change in the dissolution tended to level off after a specific surface area of $4.0 \mathrm{~m}^{2} / \mathrm{g}$ or a mean cryetallite size of $480 \AA$. 


\section{RECOMMENDATIONS}

- It is recommended that a high solid-to-liquid ratio be be used if a high plutonium concentration ( $\mathrm{g} \mathrm{Pu} / \mathrm{l} / \mathrm{hr}$ ) is desired.

- It is reconmended that a low solid-to-liquid ratio be used if a high percentage of dissolved plutonium is desired.

- It is reconmended that scrap metal be burned by a method which will give an oxide that has a specific surface area greater than $3.5 \mathrm{~m}^{2} / \mathrm{g}$ and a mean crystallite size less than $250 \AA$.

- It is recommended that a hydrochloric acid solvent system be used for maximum rate of dissolution. The hydrochloric acid system should contain an appropriate reducing agent and a small amount of Auoride ion as a complexing agent.

\section{EXPERIMENTAL PROCEDURE}

Random samples (each weighing $250 \mathrm{~g}$ ) of plutonium oxide were taken from the production process stream over a period of 6 months. During this period 28 samples were taken. Each sample was divided into two 125-gram aliquots. One aliquot was used for the nitric acid system and one aliquot was used for the hydrochloric acid system. A sample for the specific surface area and a sample for the mean crystallite size was taken from each aliquot.

The tests were run on 15-gram, 20-gram and 25-gram portions of each aliquot. Each test portion was contacted with $100 \mathrm{ml}$ of the solvent and refluxed with continuous stirring for one hour. The test sample after dissolution was diluted to approximately $140 \mathrm{ml}$, cooled and filtered through Whatman No. 40 filter paper. The insoluble residue was washed with two molar acid until free of soluble plutonium (usually 10 washes). The combined filtrate and washings were diluted to $250 \mathrm{ml}$ volume, inixed well and analyzed by $x$-ray fuorescence and colorimetric methods for grams of plutonium per liter. The insoluble residue and filter paper were transferred to a tared crucible and ignited to $800^{\circ} \mathrm{C}$. After cooling, the ashed residue was weighed and analyzed for percent plutonium by a fusion-colorimetric method or a fusion-x-ray fuorescence method.

\section{DISCUSSION OF RESULTS}

\section{THE NITRIC ACID-CALCIUM FLUORIDE SOLVENT SYSTEM}

The Effect of the Solid-to-Liquid Ratio on the Dissolution Rate of Plutonium Oxide in Terms of the Plutonium Concentration (g Pu/l/hr)*

The 15-gram, 20-gram and 25-gram portions of the oxide were contacted with $100 \mathrm{ml}$ of $-12 \mathrm{M} \mathrm{HNO}_{3}$ $0.1 \mathrm{M} \mathrm{CaF}_{2}$ as described in the experimental procedure. These tests measured the effect of the solidto-liquid ratio on the dissolution rate of the plutonium oxide in this solvent system. Because each sample had a different specifir. surfare area and/or mean crystallite size, the effect of the solid-to-liquid ratio on the oxide dissolution was measured as a function of the specific surface area, the mean crystallite size, the mean crystallite size for a given specific surface area, and the specific surface area for a given mean crystallite size. The rate of dissolution results were measured by the plutonium concentration expressed in $\mathrm{g} \mathrm{Pu} / \mathrm{l} / \mathrm{hr}$.

As a Function of the Specific Surface Area: The results, which are presented in Table I and Figure 1, illustrate the effect of the solid-to-liquid ratio on the dissolution rate of plutonium oxide as a function of only the specific surface area. 'Table I shows 14 oxide samples tabulated in an increasing order of specific surface area with the corresponding dissolution rate $(\mathrm{g} \mathrm{Pu} / \mathrm{l})$ for a given solid-to-liquid ratio.

In general, the results show that the dissolution rate of plutonium oxide levels off at higher specific surface area as the solid-to-liquid ratio increases.

As a Function of the Mean Crystallite Size: The results shown in Table II and Figure 2 illustrate the effect of the solid-to-liquid ratio on the dissolution $(\mathrm{g} \mathrm{Pu} / \mathrm{l})$ of the oxide as a function of only the mean crystallite size. Nine oxide samples arranged in increasing order of mean crystallite size are tabulated with the corresponding dissolution for each of the three ratios. The most rapid decrease in dissolution occurs in the range of $200 \AA$ to $280 \AA$. From $280 \AA$ to $480 \AA$ the decrease is steady but more gradual. As the solid-to-liquid ratio increases, the derrease in dissolution in the range of $280 \AA$ to $480 \AA$ is more pronounced.

\footnotetext{
* Plutonium concentration ( $\mathrm{g} \mathrm{Pu} / \mathrm{l} / \mathrm{hr}$ ) is hcrcafter expressed as $\mathrm{g} \mathrm{Pu} / \mathrm{l}$. Amount of plutonium dissolved ( $\%$ dissolved in $1 \mathrm{hr}$ ) is hereafter expressed as \%.
} 
TABLE I. The Effect of the Solid-to-Liquid Ratio on the Dissolution Rate ( $\mathrm{gu} / \mathrm{l} / \mathrm{hr}$ ) of Plutonium Oxide as a Function of the Specific Surface Area.

Solvent: $-12 \mathrm{M} \mathrm{HNO}_{3}-0.1 \mathrm{M} \mathrm{CaF}_{2}$

Reflux Period: One Hour

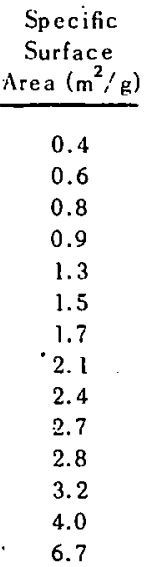

As a Function of the Mean Crystallite Size for a Given Specific Surface Area: To illustrate the effect of the interaction of the specific surface area and the mean crystallite size on the dissolution of the oxide, the data in Table III are presented. In this table the dissolution rate $(\mathrm{g} \mathrm{Pu} / \mathrm{l})$ for a given specific surface area and the data for the mean crystallite sizes are given for each solid-to-liquid ratio. The results show that for a $25 \AA$ difference in mean crystallite size the difference in dissolution rate was negligible ${ }^{3}$ for each solid-to-liquid ratio. A difference of $40 \AA$ in mean crystallite size produces a negligible difference in dissolution rate for the $150 \mathrm{~g} / \mathrm{l}$ ratio, but there is an increase in the dissolution for the smaller mean crystallite size in the case of the 200 and $250 \mathrm{~g} / \mathrm{l}$ solidto-liquid ratio. A $70 \AA$ difference shows a negligible difference in dissolution for each ratio.

\footnotetext{
${ }^{3}$ The precision in determining the plutonium concentration is $\pm 5 \%$.
}

Sulid-lu-Liquid Ratio (g/l)

\begin{tabular}{cc}
\hline$\frac{200}{\mathrm{Pu} \text { Conc. }(\mathrm{g} \mathrm{Pu} / \mathrm{l})}$ & $\frac{250}{\mathrm{Pu} \text { Conc. }(\mathrm{g} \mathrm{Pu} / \mathrm{l})}$ \\
\hline 71 & 77 \\
75 & 84 \\
82 & 91 \\
83 & 94 \\
90 & 102 \\
101. & 104 \\
106 & 106 \\
& 116 \\
112 & 118 \\
120 & 120 \\
& 132 \\
& 135
\end{tabular}

In general, the results indicate that for small changes (25-70 $\AA$ ) in the mean crystallite size, for a given specific surface area, there is a negligible change in the dissolution for each solid-to-liquid ratio. In the case of greater changes $(100-200 \AA)$ in the mean crystallite size, for a given specific surface area, there would probably be significant changes in the rate of dissolution; however, changes of this magnitude would. also result in differing surface areas and thus comparison would no longer be valid.

As a Function of the Specific Surface Area for a Given Mean Crystallite Size: To further illustrate the effect of the intra-action of the specific surface area and of the mean crystallite size on the rate of dissolution, the data in Table IV are presented. In this table, the dissolution, expressed in grams of plutonium per liter, for a given mean crystallite size and for the different specific surface areas is given for each solid-toliquid ratio.

TABLE II. The Effect of the Solid-to-Liquid Ratio on the Dissolution Rate ( $\mathrm{g} \mathrm{Pu} / 1 / \mathrm{hr}$ ) of Plutonium Oxide as a Function of the Mean Crystallite Size.

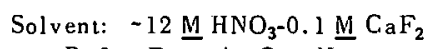

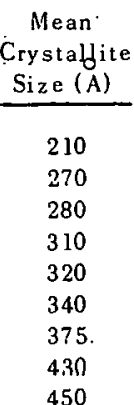

Solid-to-Liquid Ratio (g/l)

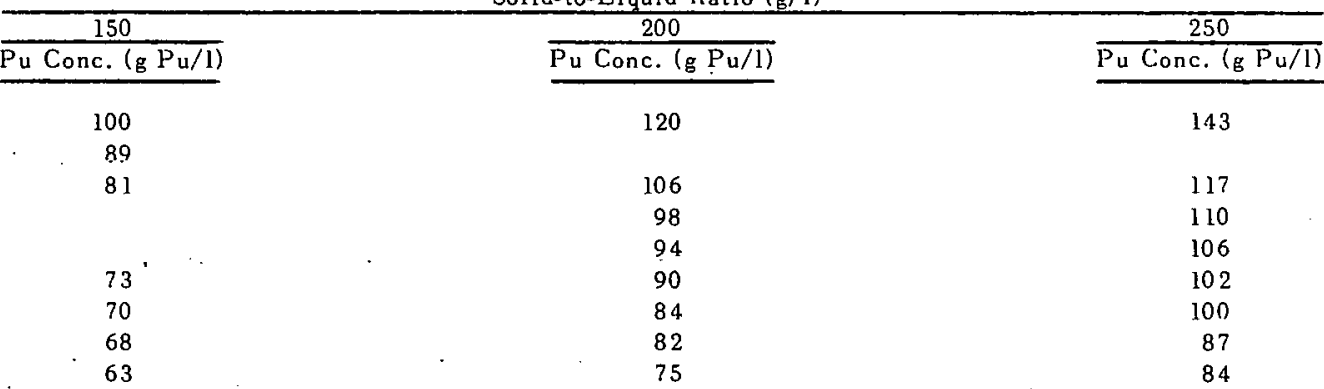




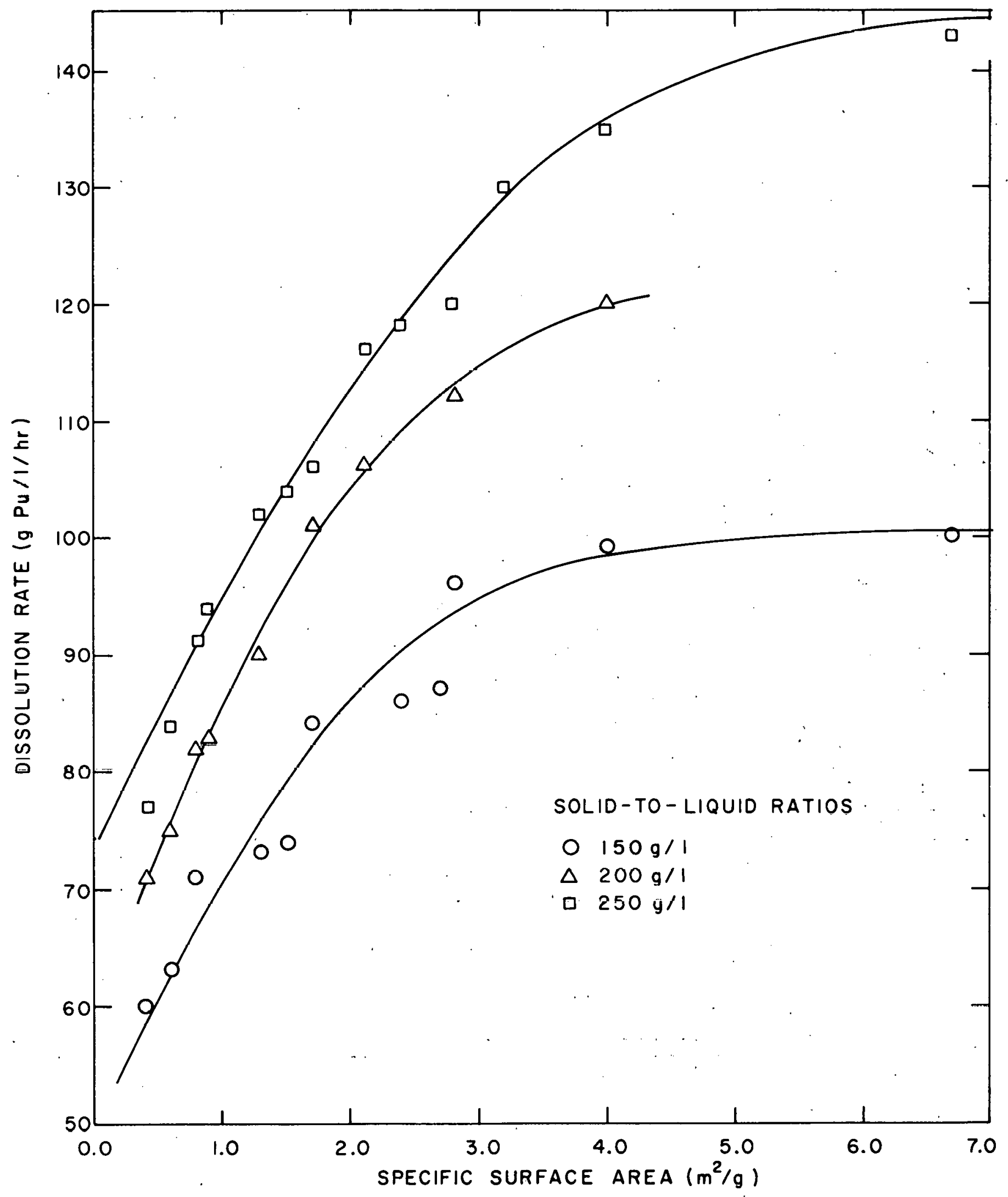

FIGURE 1. The Effect of the Solid-to-Liquid Ratio on the Dissolution Kate ( $\mathrm{Pu} / \mathrm{l} / \mathrm{hr}$ ) of Plutonium Uxide as a Function of the Specific Surface Area. Solvent: $-12 \underline{\mathrm{M}} \mathrm{HNO}_{3}-0.1$ M CaF $\mathrm{F}_{2}$. Reflux Period: One Hour. 


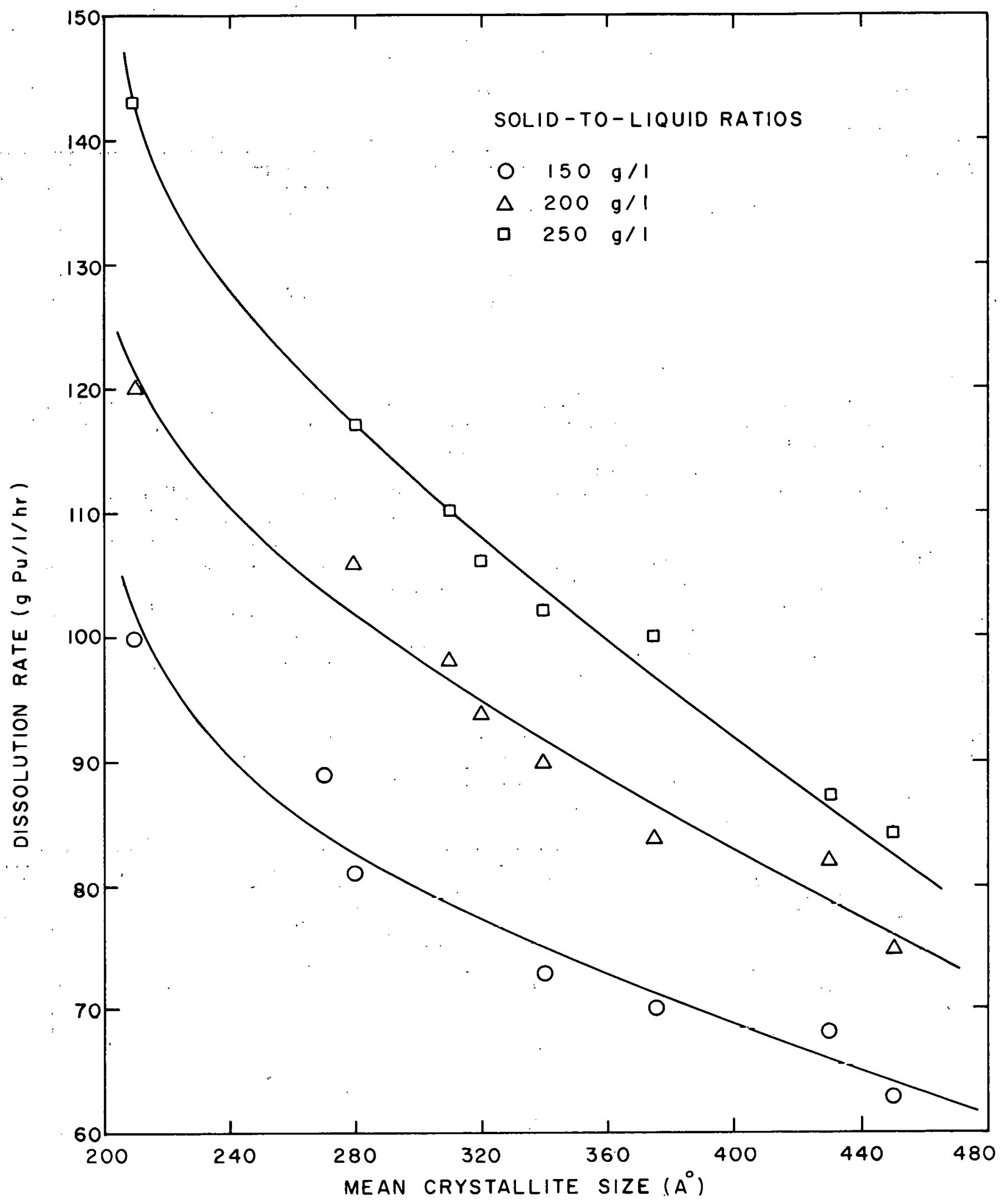

FIGURE 2. The Effect of the Solid-to-Liquid Ratin on the Dissolution Rate ( $\mathrm{g} \mathrm{Pu} / \mathrm{l} / \mathrm{hr}$ ) of Plutonium Oxide as a Function of the Mean Crystallite Size. Solvent: - $12 \mathrm{M} \mathrm{HNO}_{3}-0.1 \mathrm{M} \mathrm{CaF}_{2}$. Reflux Period: One Hour. 
TABILE: III. The Effect of the Solid-to-Liquid Ratio on the Dissolution Rate $(\mathrm{g} \mathrm{Pu} / \mathrm{l} / \mathrm{hr}$ ) of Plutonium Oxide as a Function of the Mean Crystallite Size for a Given Specific Surface Area.

Solvent: $-12 \underline{\mathrm{M}} \mathrm{HNO}_{3}-0.1 \mathrm{M} \mathrm{CaF}_{2}$

Reflux Period: One Hour

Specific

Surface

Area $\left(\mathrm{m}^{2} / \mathrm{g}\right)$

1.4

1.4

2.1

2.1

2.5

2.5

2.7

2.7
Mean

Crystaffite

Size (A)

375

400

280

320

310

380

280

350
Solid-to-Liquid Ratio (g/1)

$\frac{200}{\mathrm{Pu} \text { Conc. (g Pu/1) }}$

100
96

72

81

84

83

81

87

85
84

106

94

98

98

102

101 $\frac{250}{\text { Pu Conc. (g Pu/1) }}$

116

104

111

110

117

109
A difference of $0.4 \mathrm{~m}^{2} / \mathrm{g}$ shows no significant change in dissolution rate for any of the solid-to-liquid ratios. A difference of 0.6 to $1.9 \mathrm{~m}^{2} / \mathrm{g}$ shows a significant increase in the dissolution for each ratio as the specific surface area increases. In the case of the three oxides, in Table IV, having a mean crystallite size of $280 \AA$ and specific surface areas of $2.1,2.7$ and 2.8 $\mathrm{m}^{2} / \mathrm{g}$, the difference of $0.6 \mathrm{~m}^{2} / \mathrm{g}$ results in a negligible difference in dissolution for the 200 and $250 \mathrm{~g} / \mathrm{l}$ ratios. However, in the case of the $150 \mathrm{~g} / \mathrm{l}$ ratio there is a significant difference in the dissolution as the specific surface area increases. There is no explanation for the large increase in the rate of dissolution for the small ${ }^{4}$ increase $\left(0.1 \mathrm{~m}^{2} / \mathrm{g}\right)$ in specific surface area for the two samples having specific surface areas of 2.7 and $2.8 \mathrm{~m}^{2} / \mathrm{g}$.

In general, specific surface area differences greater than $0.6 \mathrm{~m}^{2} / \mathrm{g}$ for a given mean crystallite size, result in significant differences in the dissolution for all three solid-to-liquid ratios. The results show that the dissolution, in terms of $\mathrm{g} \mathrm{Pu} / \mathrm{l}$, is more sensitive to changes in the specific surface area than to changes in the mean crystallite size.

\footnotetext{
${ }^{4}$ The precision of the specific surface area determination is $\pm 10 \%$.
}

TABLEIV. The Effect of the Solid-to-Liquid Ratio on the Dissolution Rate ( $\mathrm{g} \mathrm{Pu} / \mathrm{l} / \mathrm{hr}$ ) of Plutonium Oxide as a Function of the Specific Surface Area for a Given Mean Cryatallite Size.

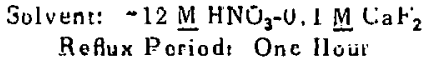

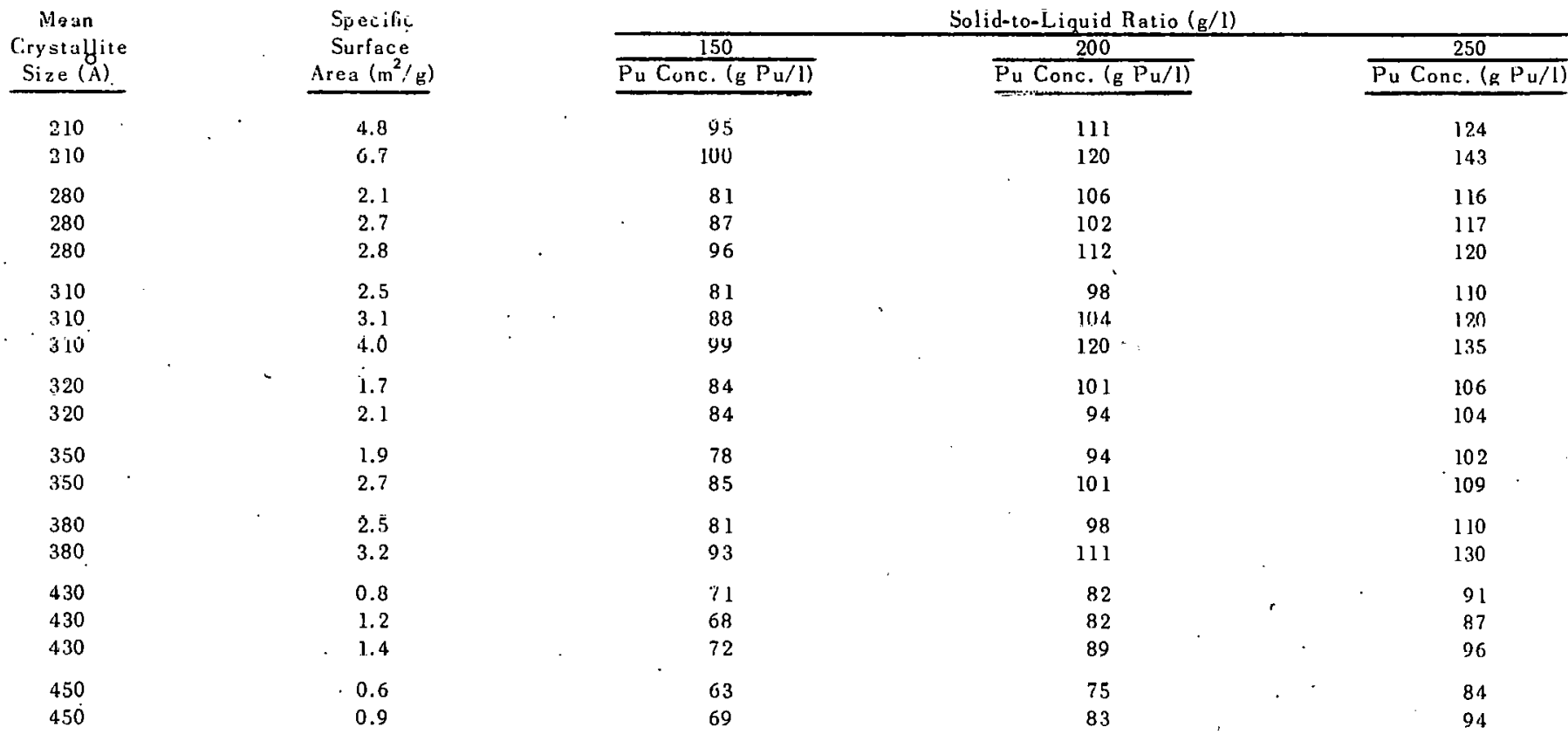


TABLE V. The Effect of Solid-to-Liquid Ratio on the Dissolution Rate (\% dissolved in $1 \mathrm{hr}$ ) of Plutonium Oxide as a Function of the Specific Surface Area.

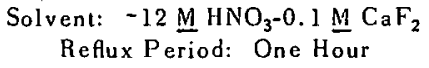

\begin{tabular}{|c|c|c|}
\hline $\begin{array}{c}\text { Specific } \\
\text { Surface } \\
\text { Area }\left(\mathrm{m}^{2} / \mathrm{g}\right)\end{array}$ & & $\frac{150}{\text { Amount of } \mathrm{Pu} \mathrm{D}}$ \\
\hline 0.4 & & 44. \\
\hline 0.6 & & 46.3 \\
\hline 0.8 & & $\Rightarrow \quad 53.0$ \\
\hline 0.9 & & \\
\hline 1.3 & & 56. \\
\hline 1.5 & $\therefore \quad \ldots$ & \\
\hline 1.7 & & 61 . \\
\hline 2.1 & & 63. \\
\hline 2.4 & & 64. \\
\hline $2.7^{\circ}$ & & 65.4 \\
\hline 2.8 & & 67. \\
\hline 3.2 & & 67.4 \\
\hline 3.3 & & 70.8 \\
\hline 3.6 & & \\
\hline 3.8 & & 71.7 \\
\hline 4.0 & & 73.9 \\
\hline 4.8 & & 74.8 \\
\hline 6.7 & & \\
\hline
\end{tabular}

Specific Surface

The Effect of the Solid-to-Liquid Ratio on the Dissolution Rate of Plutonium Oxide in Terms of the Amount of Plutonium Dissolved (\% dissolved in $1 \mathrm{hr}$ )

The dissolution of the oxide was also measured by calculating the amount of plutonium dissolved and expressing it in percent.

As a Function of the Specific Surface Area: The results, which are presented in Table $\mathrm{V}$ and Figure 3, illustrate the effect of the solid-to-liquid ratio on the dissolution of plutonium oxide, in terms of the amount of plutonium dissolved (\%), as a function of the specific surface area. Eighteen oxide samples arranged
Solid-to-Liquid Ratio (g/l)

$\begin{array}{cc}\frac{200}{\text { Amount of Pu Dissolved (\%) }} & \frac{250}{\text { Amount of Pu Dissolved (\%) }} \\ 39.9 & 34.5 \\ 42.8 & 38.2 \\ 45.8 & 41.6 \\ 46.9 & 42.5 \\ 51.7 & 46.2 \\ 52.9 & 46.6 \\ 56.1 & 48.6 \\ 58.6 & 52.2 \\ & 53.2 \\ 60.5 & 54.2 \\ 61.0 & 56.1 \\ 63.6 & 57.5 \\ 69.4 & \\ 70.2 & 60.3 \\ \end{array}$

in an increasing order of specific surface area are tabulated along with the corresponding dissolution. (\% dissolved) for a given solid-to-liquid ratio. In general, the results show that dissolution levels off at approximately the same specific surface area as the solid-to-liquid ratio increases.

As a Function of the Mean Crystallite Size: Table VI and Figure 4 illustrate the effect of the solid-to-liquid ratio on the dissolution (\% dissolved) of the oxide as a function of only the mean crystallite size. Eleven oxide samples arranged in increasing order of mean crystallite size are tabulated along with the corresponding dissolution for each of the three ratios.

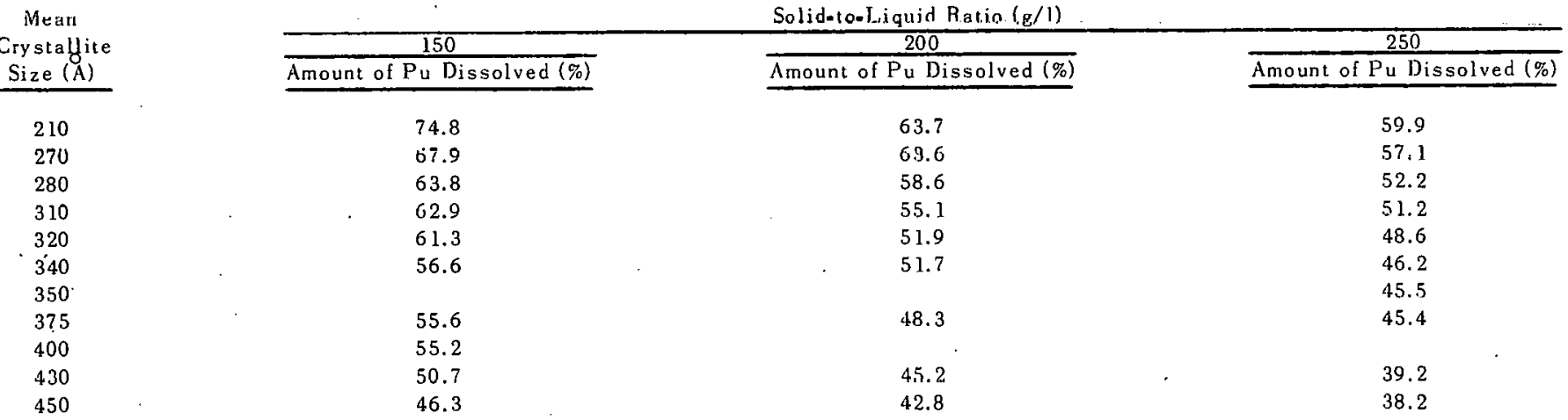




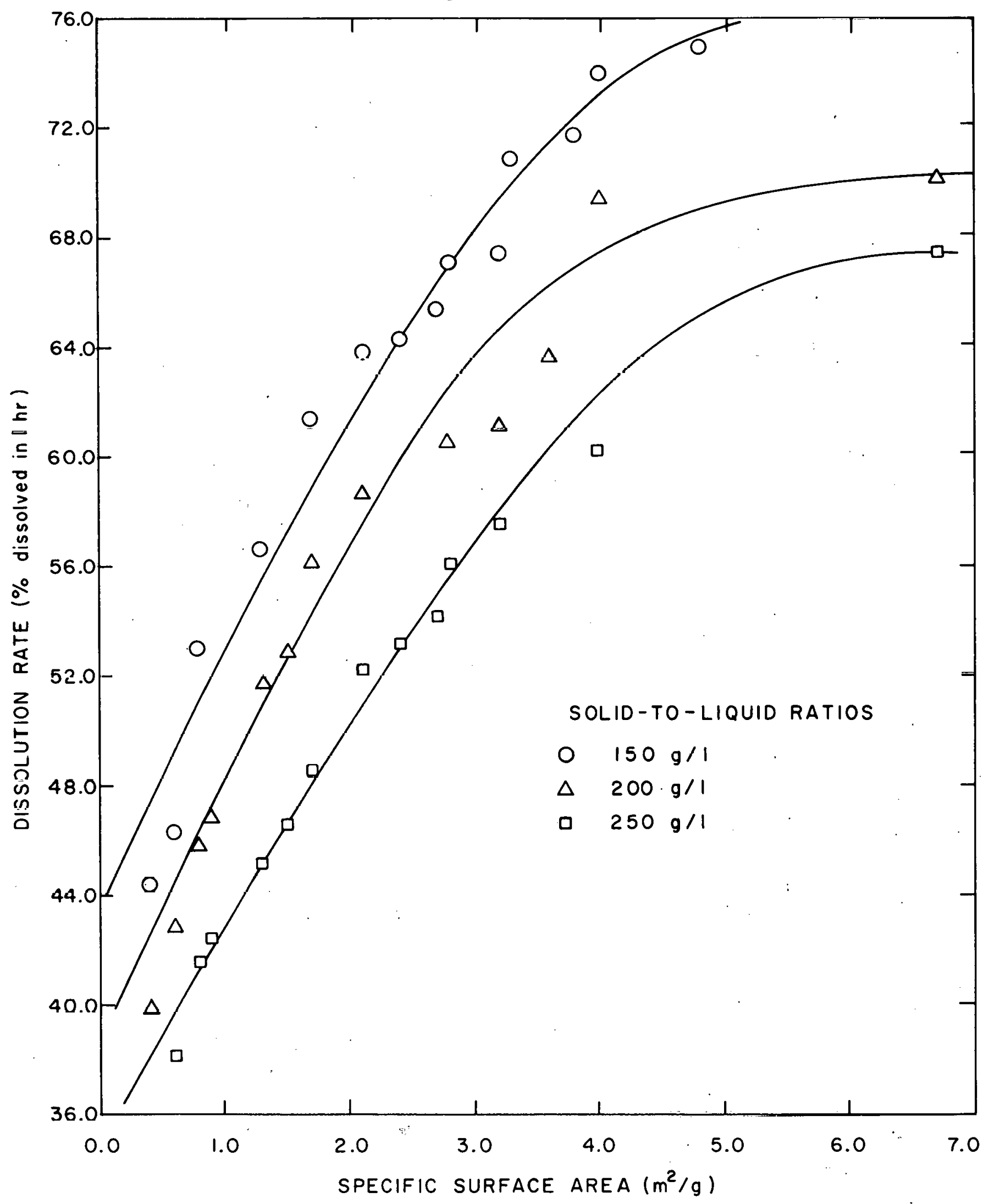

FIGURE 3. The Effect of the Solid-to-Liquid Ratio on the Dissolution Rate (\% dissolved in, $1 \mathrm{hr}$ ) of Plutonium Oxide as a Function of the Specific Surface Area. Solvent: $-12 \underline{\mathrm{M}} \mathrm{HNO}_{3}-0.1 \underline{\mathrm{M}} \mathrm{CaF}_{2}$. Reflux Period: One Hour. 


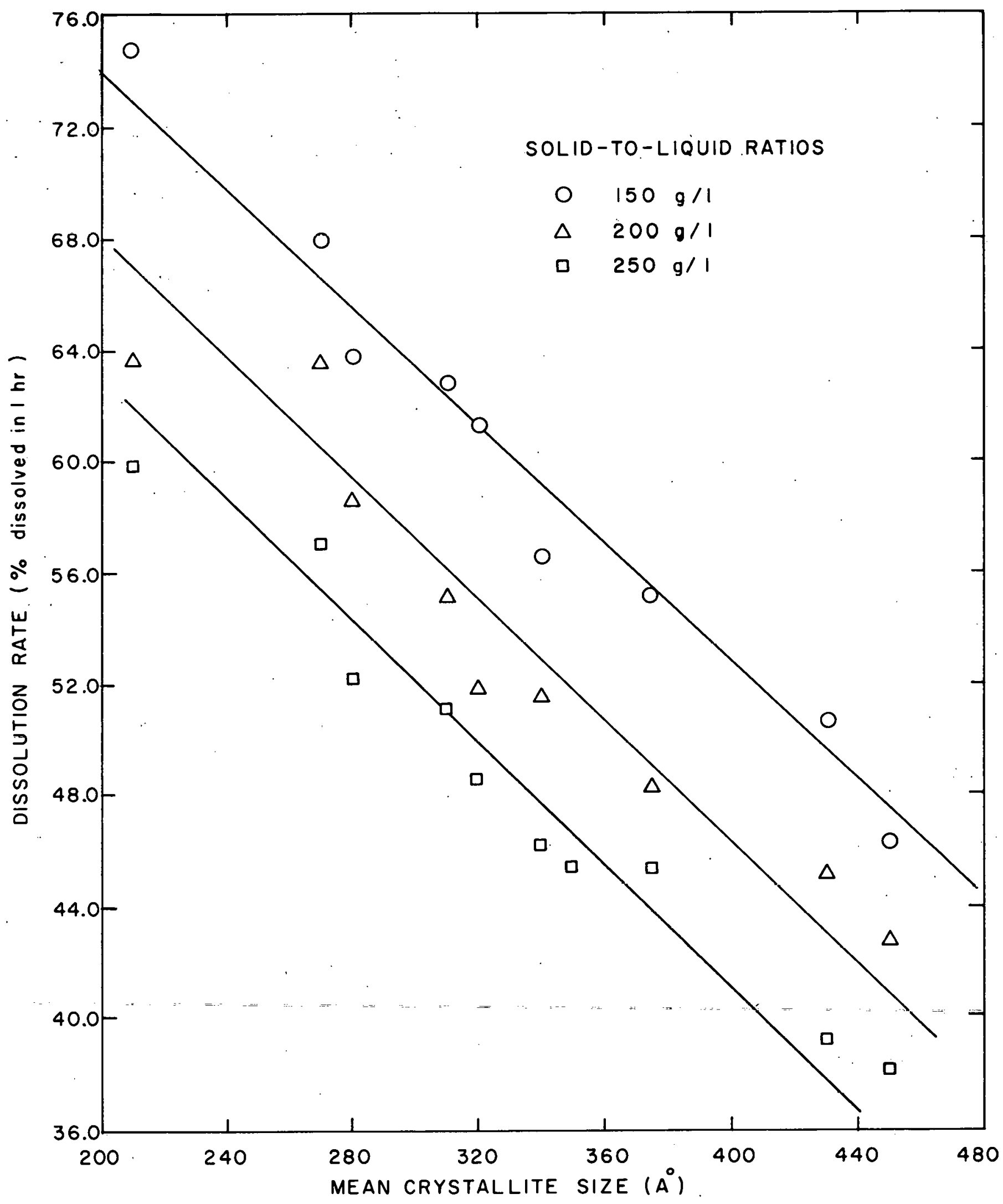

FIGURE 4. The Effect of the Solid-to-Liquid Ratio on the Dissolution Rate (\% dissolved in 1 hr) of Plutonium Oxide as a Function of the Mean Crystallite Size. Solvent: $-12 \underline{M} \mathrm{HNO}_{3}-0.1 \underline{\mathrm{M}} \mathrm{CaF}_{2}$. Reflux Period: One Hour. 
TABLE VII. The Effect of the Solid-to-Liquid Ratio on the Dissolution Rate (\% dissolved in 1 hr) of Plutonium Oxide as a Function of the Mean Crystallite Size for a Given Specific Surface Area.

Solvent: $-12 \underline{\mathrm{M}} \mathrm{HNO}_{3}-0.1 \underline{\mathrm{M}} \mathrm{CaF}_{2}$ Reflux Period: One Hour

\begin{tabular}{cc}
$\begin{array}{c}\text { Specific } \\
\text { Surface } \\
\text { Area }\left(\mathrm{m}^{2} / \mathrm{g}\right)\end{array}$ & $\begin{array}{c}\text { Mean } \\
\text { Crystallite } \\
\text { Size (A) }\end{array}$ \\
\hline 1.4 & 375 \\
1.4 & 430 \\
2.1 & 280 \\
2.1 & 320 \\
2.5 & 310 \\
2.5 & 380 \\
2.7 & 280 \\
2.7 & 350
\end{tabular}

\begin{tabular}{c}
$\frac{150}{\text { Amount of Pu Dissolved (\%) }}$ \\
\hline 55.6 \\
53.7 \\
63.8 \\
61.3 \\
62.9 \\
60.4 \\
65.4 \\
63.4
\end{tabular}

The decrease in dissolution is linear for each solidto-liquid ratio. The rate of decrease in the dissolution is the same for each ratio.

As a Function of the Mean Crystallite Size for a Given Specific Surface Area: To illustrate the effect of the interaction of the specific surface area and the mean crystallite size on the dissolution of the oxide, the data in Table VII are presented. In this table the rate of dissolution (\% dissolved) for a given specific surface area and for the different mean crystallite sizes is given for each solid-to-liquid ratio. The results show that for a $40 \AA$ difference in mean crystallite size

Solid-to-Liquid Ratio (g/l)

\begin{tabular}{cc}
$\frac{200}{\text { Amount of Pu Dissolved (\%) }}$ \\
\hline 48.3 & $\frac{250}{\text { Amount of Pu Dissolved (\%) }}$ \\
49.0 & 45.4 \\
58.6 & 43.2 \\
51.9 & 52.2 \\
55.1 & 46.4 \\
55.0 & 51.2 \\
58.0 & 49.5 \\
56.4 & 54.2 \\
& 51.6
\end{tabular}

the difference in dissolution was negligible for the 150 $\mathrm{g} / \mathrm{l}$ solid-to-liquid ratio, but that the difference in the rate of dissolution was significant for the other two solid.to-liquid ratios. A $70 \AA$ or less difference in . mean crystallite size results in a negligible difference in the dissolution for each solid-to-liquid ratio.

As a Function of the Specific Surface Area for a Given Mean Crystallite Size: To further illustrate the effect of the interaction of the specific surface area and the mean crystallite size on the dissolution, the data in Table VIII are presented. In this table the dissolution, expressed in the amount of plutonium dissolved (\%),

TABLE VIII. The Effect of the Solid-to-Liquid Ratio on the Dissolution Rate (\% dissolved in $1 \mathrm{hr}$ ) of Plutonium Oxide as a Function of the Specific Surface Area for a Given Mean Crystallite Size.

Solvent: $-12 \mathrm{M} \mathrm{HNO}_{3}-0.1 \mathrm{M} \mathrm{CaF}$ HeHux Perind: One Hour

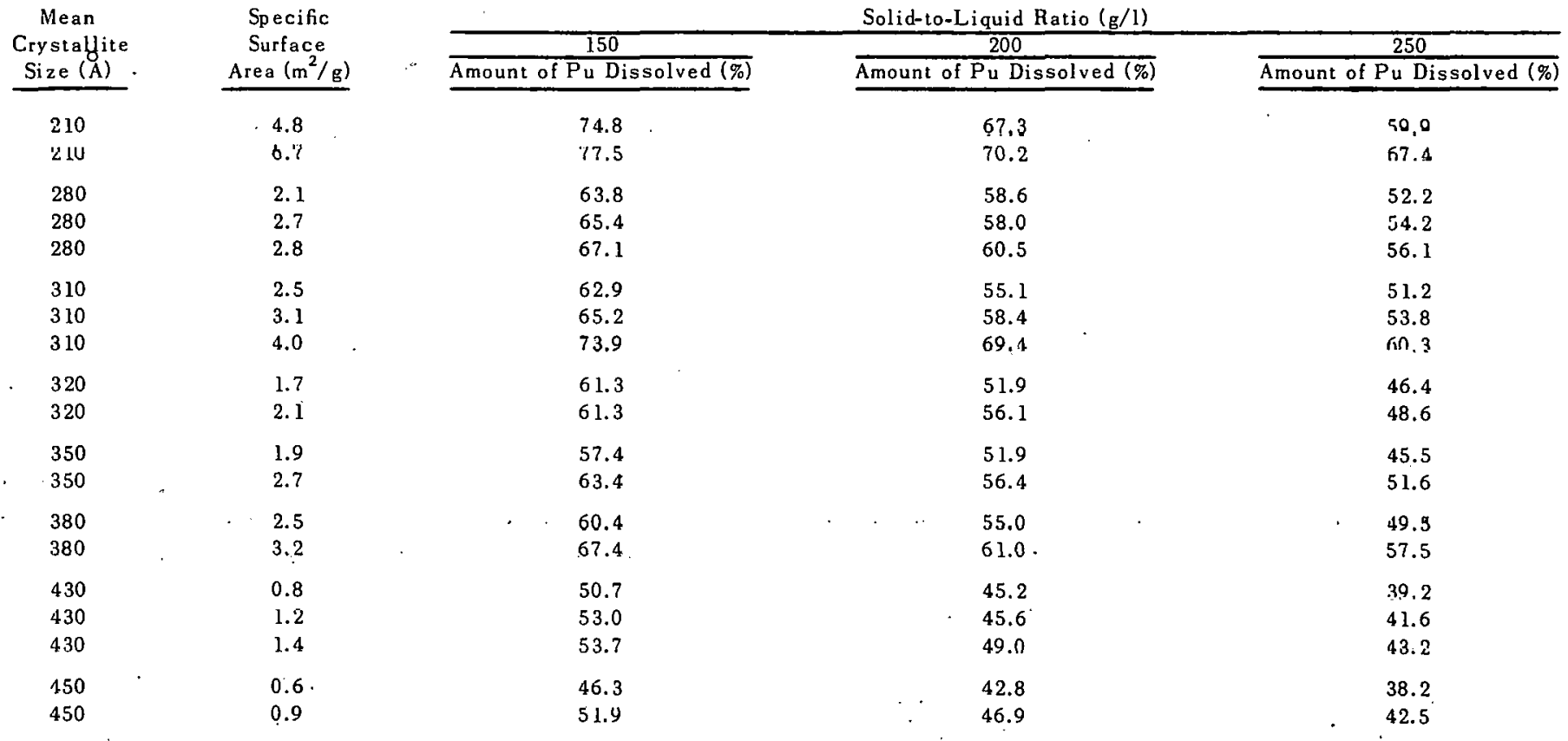


TABLE IX. The Effect of the Solid-to-Liquid Ratio on the Dissolution Rate

( $\mathrm{g} \mathrm{Pu} / \mathrm{l} / \mathrm{hr}$ ) of Plutonium Oxide as a Function of the Specific Surface Area.

Solvent: $-12 \underline{\mathrm{M} \mathrm{HCl}}-0.5 \underline{\mathrm{M} \mathrm{SnCl}} \mathrm{Sl}_{2}$

Reflux Period: One Hour

Specific

Surface

Area $\left(\mathrm{m}^{2} / \mathrm{g}\right)$

0.4
0.6
0.8
0.9
1.2
1.3
1.4
1.7
2.1
2.4
3.6
6.7

for a given mean crystallite size and for the different specific surface areas is given for each solid-toliquid ratio.

The results show that an increase of $0.8 \mathrm{~m}^{2} / \mathrm{g}$ or greater in the specific surface area for a given mean crystallite size results in a significant increase in the dissolution of the oxide for each solid-to-liquid ratio. For smaller differences the change in dissolution is dependent upon the relative specific surface area, mean crystallite size, and the solid-to-liquid ratio.

\section{THE HYDROCHLORIC ACID-STANNOUS CHLORIDE SOLVENT SYSTEM}

The Effect of the Solid-to-Liquid Ratio on the Dissolution Rate of Plutonium Oxide in Terms of the Plutonium Concentration (g Pu/l/hr)

The 15-gram, 20-gram and 25-grain portione of the oxide were allowed to rcact with $100 \mathrm{ml}$ of $-12 \mathrm{M} \mathrm{HCl}$ $0.5 \mathrm{M} \mathrm{SnCl}_{2}$ as described in the experimental procedure. The se tests measured the effect of the solid-toliquid ratio on the dissolution rate of the plutonium
Solid-to-Liquid Ratio (g/1)

\begin{tabular}{cr}
$\frac{200}{\mathrm{Pu} \text { Conc. }(\mathrm{gPu} / 1)}$ & 250 \\
\cline { 2 - 2 } 54 & Pu Conc. \\
84 & 70 \\
98 & 101 \\
& 131 \\
100 & 132 \\
102 & \\
& \\
112 & 135 \\
131 & 138 \\
140 & 160 \\
152 & 179 \\
162 & 194 \\
& 206
\end{tabular}

oxide in this solvent system. Because each sample had a different specific surface area and/or mean crystallite size the effect of the solid-to-liquid ratio on the oxide dissolution was measured as a function of the specific surface area, the mean crystallite size, the mean crystallite size for a given specific surface area, and the specific surface area for a given mean crystallite size. The dissolution results were measured by the plutonium concentration expressed in $\mathrm{g} \mathrm{Pu} / \mathrm{l}$.

As a Function of the Specific Surface Area: The effect of the specific surface area on the dissolution of the oxide is shown in Table IX and Figure 5. Twelve oxide samples arranged in an increasing order of specific surface area are tabulated along with the corresponding dissolution $(\mathrm{g} \mathrm{Pu} / \mathrm{l})$ for a given solid-toliquid ratio. In general, the results show that the dissolution levels off at approximately the same specific surface area (i.e. $6.7 \mathrm{~m}^{2} / \mathrm{g}$ ) for each solidto-liquid ratio.

As a Function of the Mean Crystallite Size: Table $X$ and Figure 6 illustrate the effect of the solid-to-liquid ratio on the dissolution $(\mathrm{g} \mathrm{Pu} / \mathrm{l})$ of the oxide as a

TABLE X. The F.ffect of the Solid-to-Liquid Ratio on the Dissolution Rate ( $\mathrm{g} \mathrm{Pu} / \mathrm{l} / \mathrm{hr}$ ) of Plutonium Oxide as a Function of the Mean Crystallite Size.

Solvent: $-12 \mathrm{M} \mathrm{HCl}-0.5 \mathrm{M} \mathrm{SnCil_{2 }}$

Reflux Period: One Hour

\begin{tabular}{c} 
Mean \\
Crystallite \\
Size (A) \\
\hline 210 \\
280 \\
310 \\
320 \\
375 \\
400 \\
450
\end{tabular}

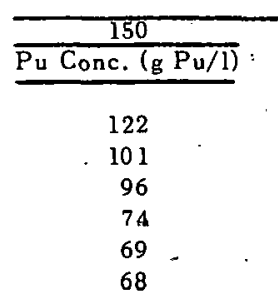

Solid-to-Liquid Ratio (g/1)

\begin{tabular}{cc}
$\frac{200}{\mathrm{Pu} \text { Conc. (g Pu/1) }}$ & $\frac{250}{\mathrm{Pu} \text { Conc. (g Pu/1) }}$ \\
\hline 162 & 206 \\
131 & 160 \\
124 & 132 \\
92 & 114 \\
88 & 110 \\
84 & 101
\end{tabular}




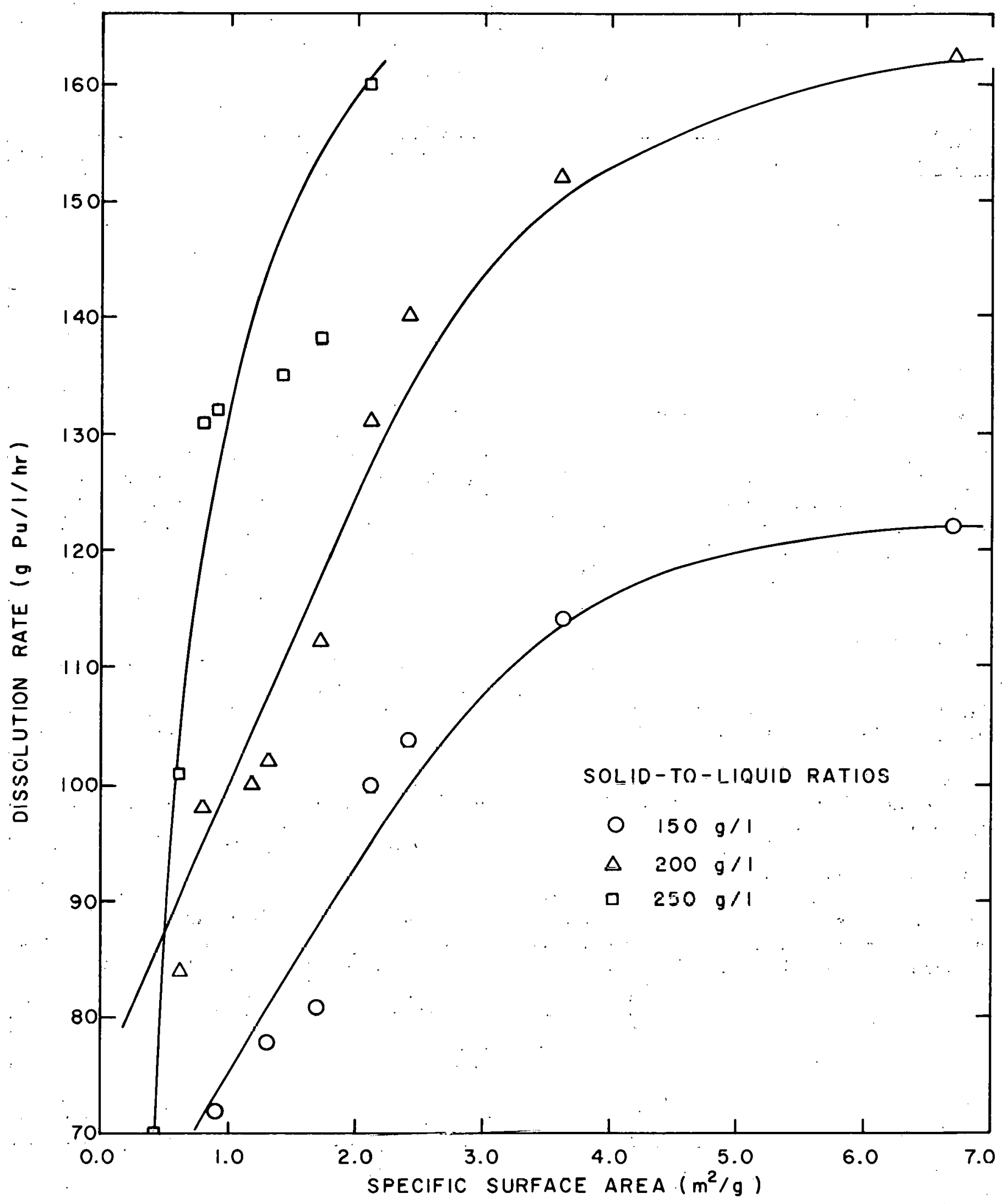

FIGURE 5. The Effect of the Solid-to-Liquid Ratio on the Diseolution Rate ( $\mathrm{g} \mathrm{Pu} / \mathrm{l} / \mathrm{hr}$ ) of Plutonium Oxide as a Function of the Specific Surface Area. Solvent: $-12 \underline{\mathrm{M}} \mathrm{HCl}-0.5 \mathrm{M} \mathrm{SnCl} \mathrm{L}_{2}$. Reflux Period: One Hour. 


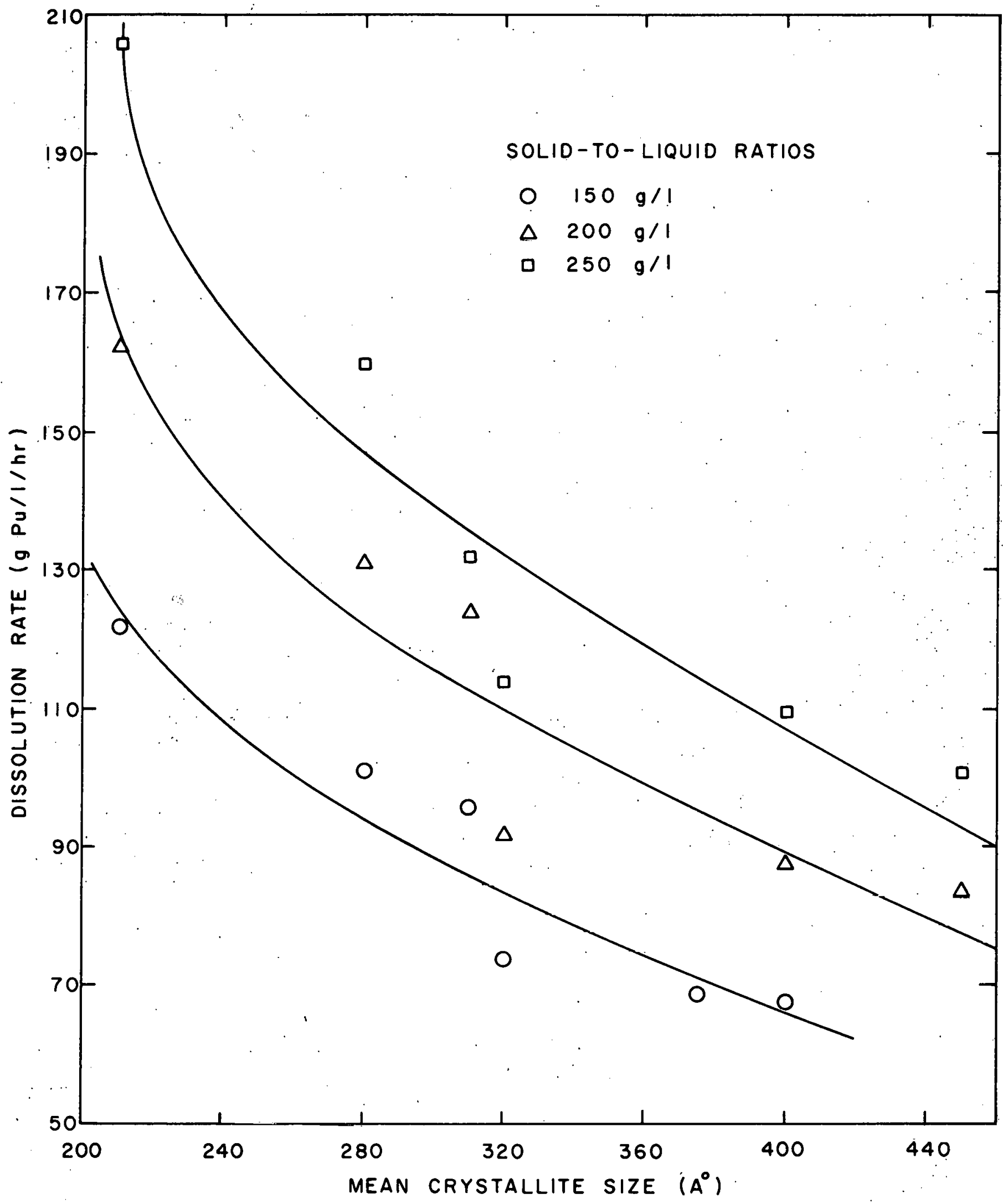

FIGURE 6. The Effect of the Solid-to-Liquid Ratio on the Dissolution Rate ( $\mathrm{g} \mathrm{Pu} / \mathrm{l} / \mathrm{hr}$ ) of Plutonium Oxide as a Function of the Mean Crystallite Size. Solvent: $-12 \underline{\mathrm{M}} \mathrm{HCl}-0.5 \underline{\mathrm{M} \mathrm{SnCl}} \mathrm{L}_{2}$. Reflux Period: One Hour. 
function of only the mean crystallite size. Seven oxide samples arranged in increasing order of mean crystallite size are tabulated along with the corresponding dissolution for each of the three ratios.

The rate of decrease in dissolution is most rapid between 200 and $280 \AA$. From 280 to $480 \AA$ the decrease is steady but more gradual. The rate of decrease in the dissolution is approximately the same for all the three solid-to-liquid ratios.

As a Function of the Mean Crystallite Size for a Given Specific Surface Area: To illustrate the effect of the interaction of the specific surface area and the mean crystallite size on the dissolution rate of the oxide, the data in Table XI are presented. In this table the dissolution ( $\mathrm{g} \mathrm{P} y / \mathrm{l})$ for a given specifio ourface area and different mean crystallite sizes is given for each solid-to-liquid ratio. In general, small changes ( 40 to $70 \AA$ ) in the mean crystallite size produce a negligible change in the rate of dissolution of the oxide having a given specific surface area. However, in the case of the samples having a specific surface area of $2.1 \mathrm{~m}^{2} / \mathrm{g}$ an increase of $40 \mathrm{~A}$ does produce a significant decrease in the dissolution for all three ratios. This fact also applies to the 150 and $250 \mathrm{~g} / \mathrm{l}$ ratios for the samples having a specific surface area of $1.4 \mathrm{~m}^{2} / \mathrm{g}$ and a difference of $55 \AA$ in mean crystallite size. There is no known explanation for this behavior.

As a Function of the Specific Surface. Area for a Given Mean Crystallite Size: The data in Table XII further illustrate the effect of the interaction of the specific suiface area and the mean crystallite size on the dissolution of plutonium oxide. In Table XII, the rate of dissolutions, expressed in grams of plutonium per liter per hour, for a given mean crystallite size and a different specific surface area, are given for each solid-to-liquid ratio. The results show that an increase of $0.8 \mathrm{~m}^{2} / \mathrm{g}$ or greater in the specific surface area for a given mean crystallite size results in a significant increase in the dissolution rate of the oxide for each solid-to-liquid ratio. For increases less than $0.8 \mathrm{~m}^{2} / \mathrm{g}$ the significance of the change in dissolution rate is dependent upon the relative specific surface area, mean crystallite size and solidto-liquid ratio.

The Effect of the Solid-to-Liquid Ratio on the Dissolution Rate of Plutonium Oxide in Terms of the Amount of Plutonium Dissolved (\% dissolved in $1 \mathrm{hr}$ )

The Ulssolution of the uxide was also measured by calculation of the amount of plutonium dissolved in 1 hour and oxpressing it in percent of total available plutonium.

As a Function of the Specific Surface Area: The results tabulated in Table XIII and shown in Figure 7 illustrate the effect of the specific surface area on the dissolution (\% dissolved) of the oxide in the hydrochloric acid system. Figure 7 shows that the effect of specific surface area on the dissolution rate was approximately the same for each of the three solidto-liquid ratios.

As a Function of the Mean Crystallite Size: Table XIV and Figure 8 illuotratc the effect of the mean crystallite size on tho dissolution rale of plutonium oxide for each solid-to liquid ratio. The dissolution (\% dissolved) decreases as the mean crystallite size increases from 210 to $450 \AA$. The mean crystallite size effects the rate of dissolution to the same degree for earh snlid-to-liquid ratio as sluwn in Flgüre 8 .

TABLE XI. The Effect of the Solid-to-Liquid Ratio on the Dissolution Rate (g Pu/l/hr) of Plutonium Oxide as a Function of the Mean Crystallite Size for a Given Specific Surface Area.

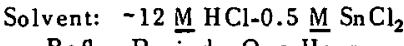

Reflux Period: One Hour

\begin{tabular}{|c|c|}
\hline $\begin{array}{c}\text { Spceilic } \\
\text { Surface } \\
\text { Area }\left(\mathrm{m}^{2} / \mathrm{g}\right) \\
\end{array}$ & $\begin{array}{c}\text { Mean } \\
\text { Crystallite } \\
\text { Size (A) } \\
\end{array}$ \\
\hline 1.4 & 375 \\
\hline 1.4 & 430 \\
\hline 2.1 & 280 \\
\hline 2.1 & 320 \\
\hline 2.5 & 310 \\
\hline 2.5 & 380 . \\
\hline 2.7 & 280 \\
\hline 2.7 & 350 \\
\hline
\end{tabular}

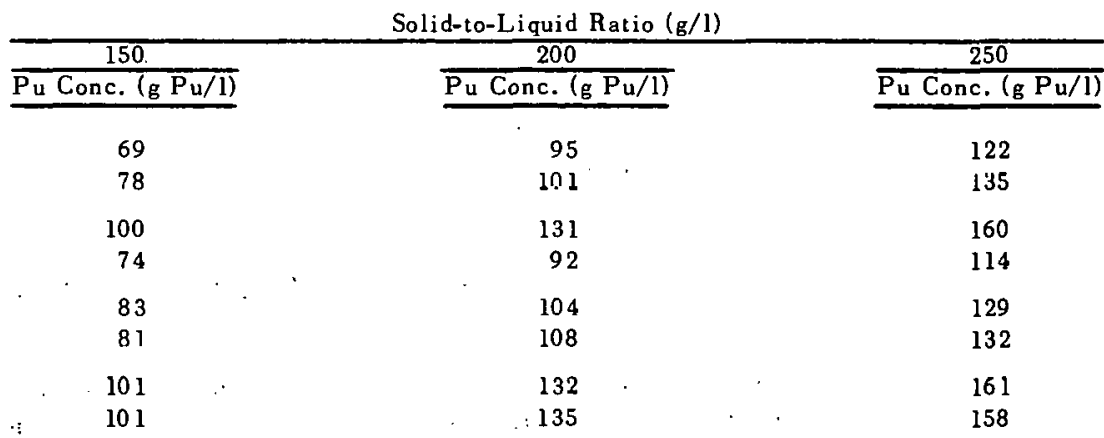


TABLE XII. The Effect of the Solid-to-Liquid Ratio on the Dissolution Rate (g Pu/l/hr) of Plutonium Oxide as a Function of the Specific Surface Area for a Given Mean Crystallite Size. Solvent: $-12 \underline{\mathrm{M}} \mathrm{HCl}-0.5 \underline{\mathrm{M} \mathrm{SnCl}} \mathrm{Sl}_{2}$
Reflux Period: One Hour

\begin{tabular}{|c|c|}
\hline $\begin{array}{c}\text { Mean } \\
\text { Crystafite } \\
\text { Size (A) }\end{array}$ & $\begin{array}{c}\text { Specific } \\
\text { Surface } \\
\text { Area }\left(\mathrm{m}^{2} / \mathrm{g}\right)\end{array}$ \\
\hline 210 & 4.8 \\
\hline 210 & 6.7 \\
\hline 280 & 2.1 \\
\hline 200 & 2.7 \\
\hline 280 & 2.8 \\
\hline 310 & 2.5 \\
\hline 310 & 3.1 \\
\hline 310 & 4.0 \\
\hline 320 & 1.7 \\
\hline 320 & 2.1 \\
\hline 350 & 1.9 \\
\hline 350 & 2.7 \\
\hline 380 & 2.5 \\
\hline 380 & 3.2 \\
\hline 430 & 0.8 \\
\hline 430 & 1.2 \\
\hline 430 & 1.4 \\
\hline 450 & 0.6 \\
\hline 450 & 0.9 \\
\hline
\end{tabular}

\begin{tabular}{r}
\hline 150 \\
\hline Pu Conc. \\
\hline 110 \\
122 \\
100 \\
101 \\
102 \\
81 \\
96 \\
112 \\
81 \\
74 \\
74 \\
101 \\
81 \\
96 \\
69 \\
70 \\
78 \\
69 \\
72
\end{tabular}

As a Function of the Mean Crystallite Size for a Given Specific Surface Area: To illustrate the effect of the interaction of the mean crystallite size and the specific surface area on the rate of dissolution, in terms of the amount of plutonium dissolved (\%), of plutonium oxide the results in Table XV are presented. In general, the results show that small changes (40-70 $\mathrm{A}$ ) in the mean crystallite size do not significantly increase the amount of plutonium dissolved for each of the three ratios. The results, for the two oxide samples having a specific surface area of $2.1 \mathrm{~m}^{2} / \mathrm{g}$, show that there is a significant increase in the rate of plutonium dissolution when the mean crystallite size increases from 280 to $320 \mathrm{~A}$. There is no known explanation for this behavior.
Solid-to-Liquid Ratio ( $g / 1)$

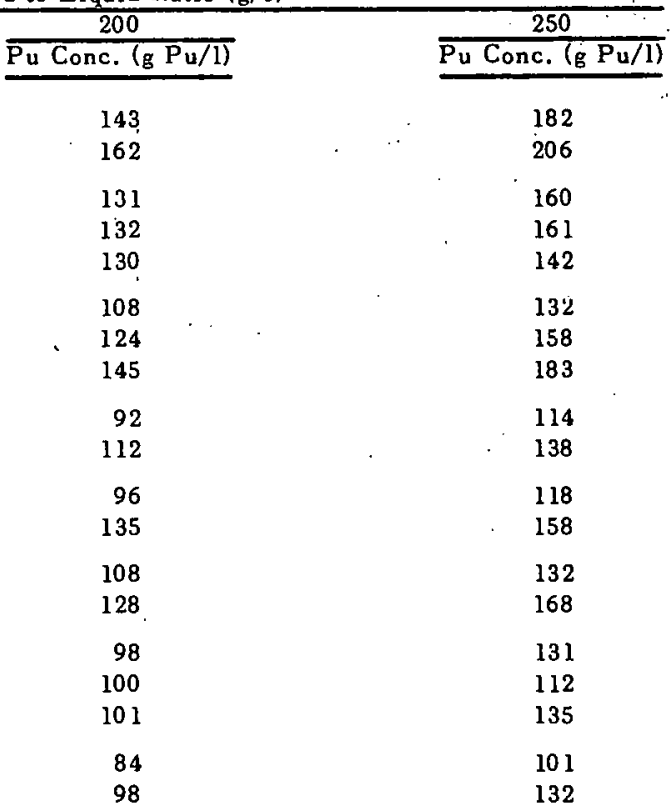

As a Function of the Specific Surface Area for a Given Mean Crystallite Size: The results in Table XVI illustrate the effect of the interaction of the specific surface area and the mean crystallite size on the dissolution rate of plutonium oxide. The results show that an increase greater than $0.8 \mathrm{~m}^{2} / \mathrm{g}$ produces a significant increase in the dissolution rate of the oxide. If the increase in the specific surface area is less than $0.8 \mathrm{~m}^{2} / \mathrm{g}$, the significance of the increase in the dissolution rate is dependent upon the relative specific surface area, the mean crystallite size, and the solid-to-liquid ratio.

TABLE XIII. The Effect of the Solid-to-Liquid Ratio on the Dissolution Rate (q dissolved in $1 \mathrm{hr}$ ) of Plutonium Oxide as a Function of the Specific Surface Area.

Solvent: $-12 \underline{\mathrm{M} \mathrm{HCl}-0.5 \mathrm{M} \mathrm{SnCl}}$

Reflux Period: One Hour

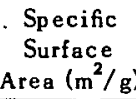

0.4

0.6

0.8

0.9

1.3

1.4

1.7

2.1

2.4

3.3

3.6

4.8

6.7
Solid-to-Liquid Ratio ( $\mathrm{g} / \mathrm{l})$

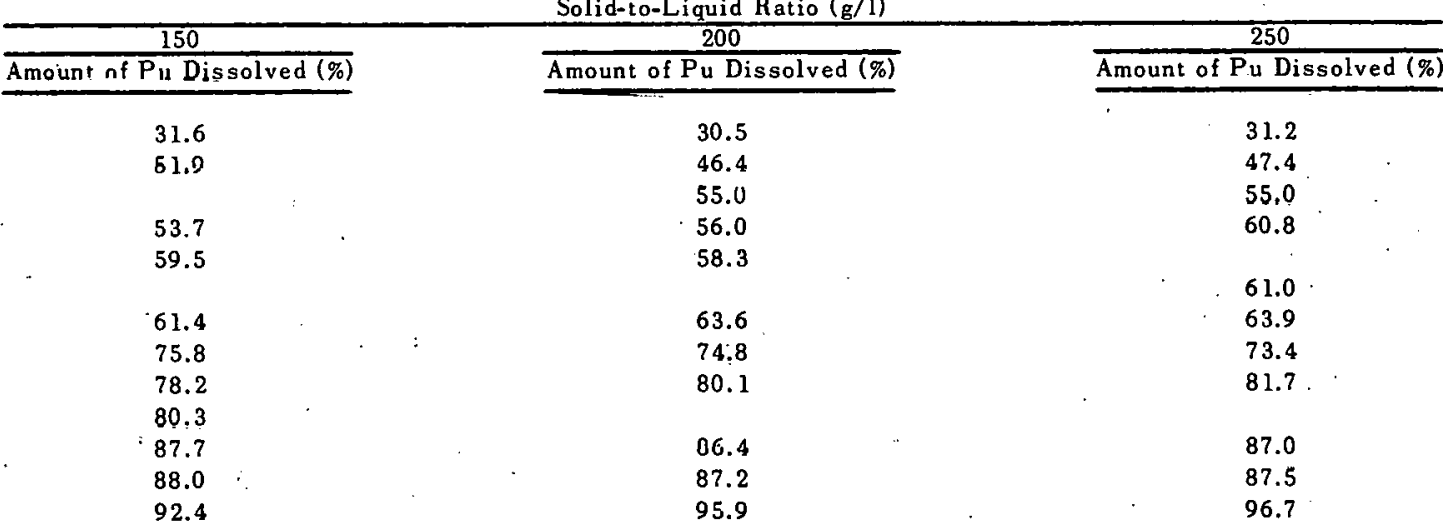


RFP-922

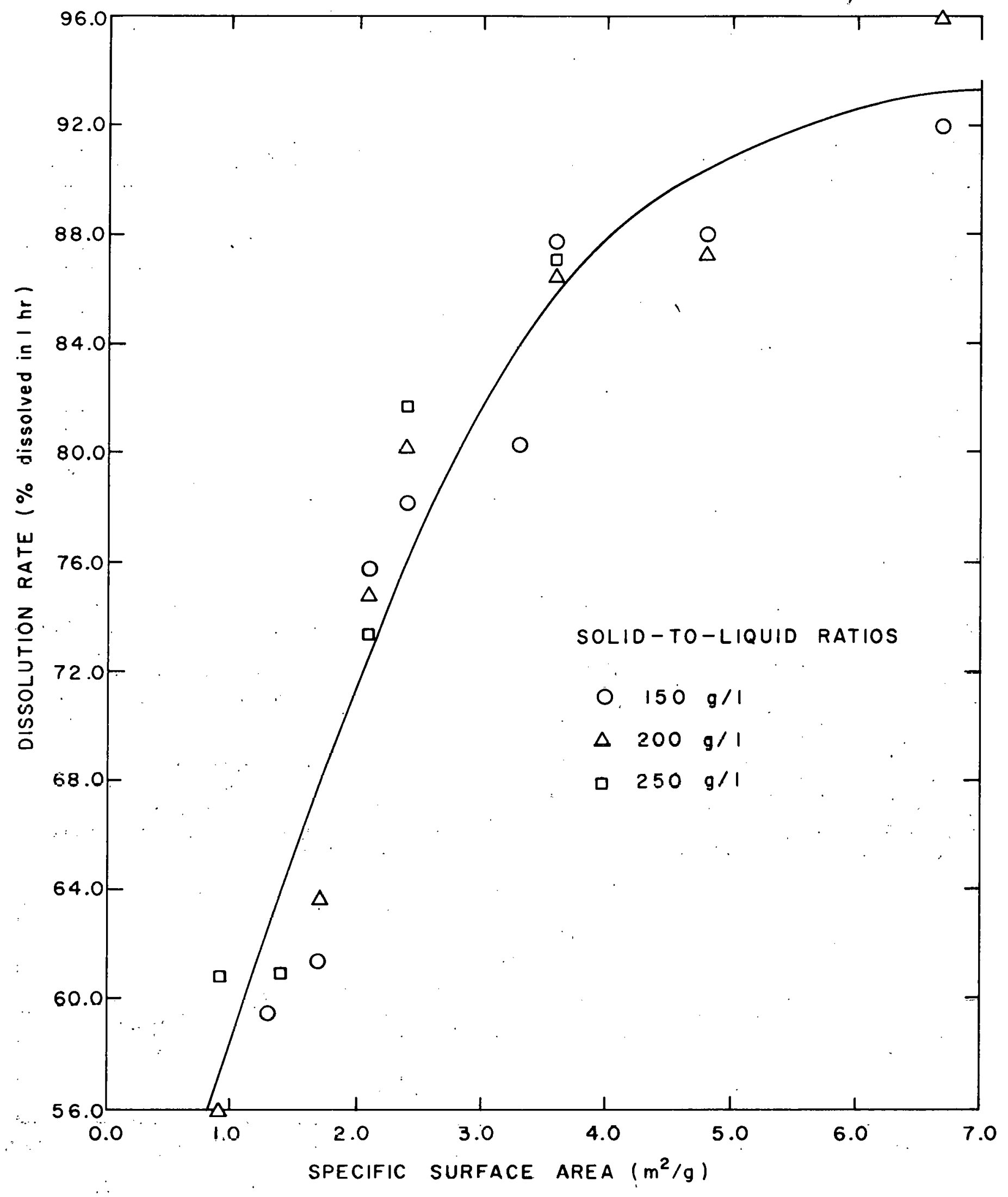

FIGURE 7. The Effect of Solid-to-Liquid Ratio on the Dissolution Rate (\% dissolved in 1 hr) of Plutonium Oxide as a Function of the Specific Surface Area. Solvent: $-12 \underline{\mathrm{M}} \mathrm{HCl}-0.5 \mathrm{M} \mathrm{SnCl}_{2}$. Reflux Period: One Hour. 


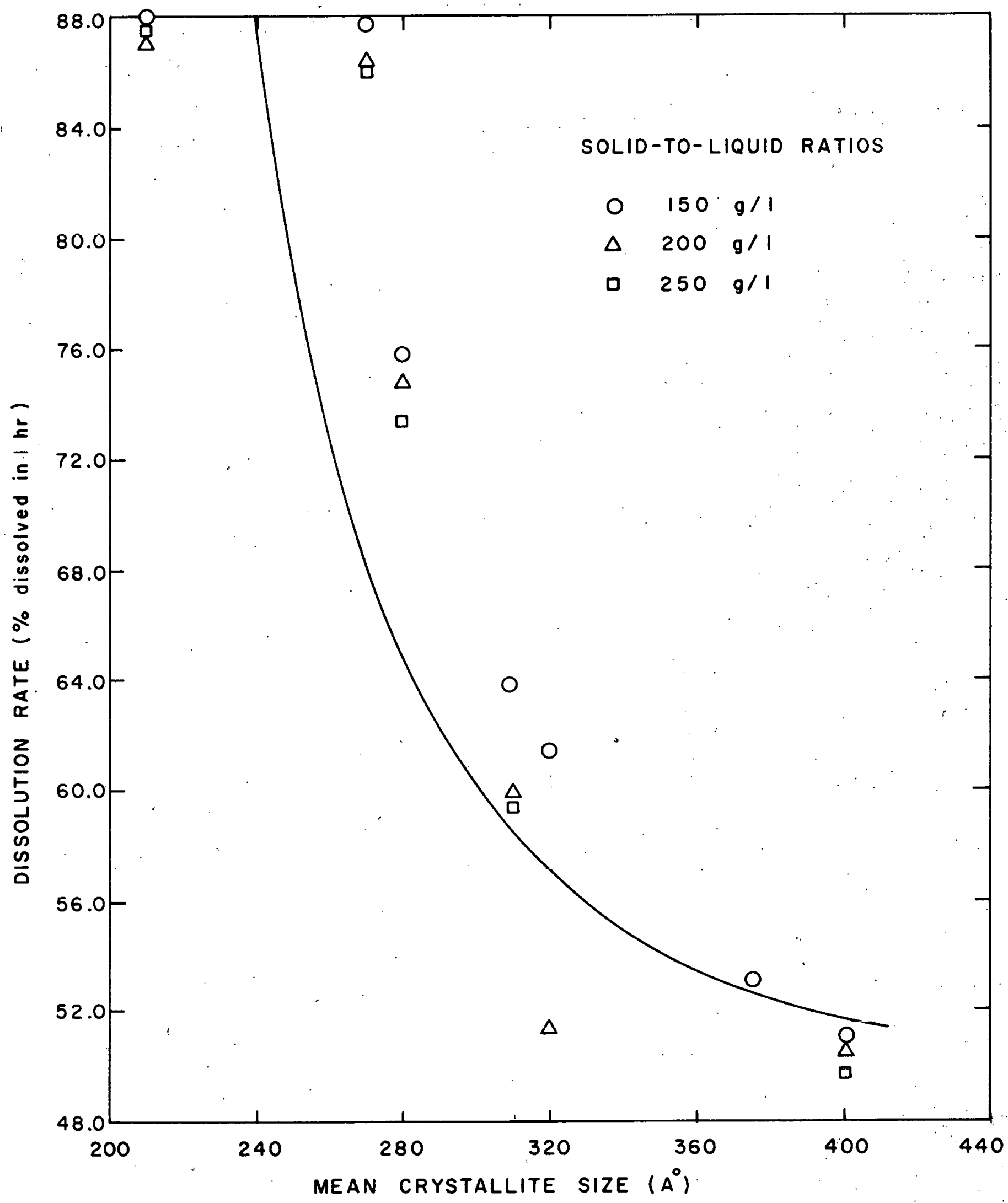

FIGURE 8. The Effect of the Solid-to-Liquid Ratio on the Dissolution Rate (\% dissolved in $1 \mathrm{hr}$ ) of Plutonium

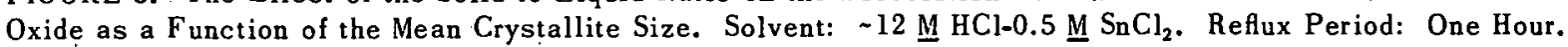


XIV. The Effect of the Solid-to-Liquid Ratio on the Dissolution Rate (\% dissolved in $1 \mathrm{hr}$ ) of Plutonium Oxide as a Function of the Mean Crystallite Size.

$$
\begin{aligned}
& \text { Solvent: }-12 \underline{\mathrm{M}} \mathrm{HCl}-0.5 \underline{\mathrm{M}} \mathrm{SnCl}_{2} \\
& \text { Reflux Period: One Hour }
\end{aligned}
$$

\begin{tabular}{|c|c|c|}
\hline$\frac{150}{\frac{\text { Amount of } \mathrm{Pu} \text { Dissolved (\%) }}{2}}$ & $\frac{200}{\text { Amount of } \mathrm{Pu} \text { Dissolved (\%) }}$ & $\frac{250}{\text { Amount of Pu Dissolved (\%) }}$ \\
\hline 88.0 & 87.2 & 87.5 \\
\hline 87.7 & $86: 4$ & 87.0 \\
\hline 75.8 & 74.8 & 73.4 \\
\hline 63.8 & 59.8 & 59.4 \\
\hline 61.4 & 51.4 & 51.4 \\
\hline 53.1 & & \\
\hline 51.1 & 50.6 & 49.8 \\
\hline & 46.4 & 47.4 \\
\hline
\end{tabular}

\begin{tabular}{l} 
Mean \\
Crystaldite \\
Size (A) \\
\hline 210 \\
270 \\
280 \\
310 \\
320 \\
375 \\
400 \\
450
\end{tabular}

TABLE XV. 'The Effect of the Solid-to-Liquid Ratio on the Dissolution Rate (\% dissolved in 1 hr) of Plutonium Oxide as a Funclion of the Mcan Cryatallite Size for a Civen Specific Surface Area.

$$
\begin{aligned}
& \text { Solvent: } \sim 12 \mathrm{M} \mathrm{HCl}-0.5 \underline{\mathrm{M}} \mathrm{SnCl}_{2} \\
& \text { Reflux Period: One Hour }
\end{aligned}
$$

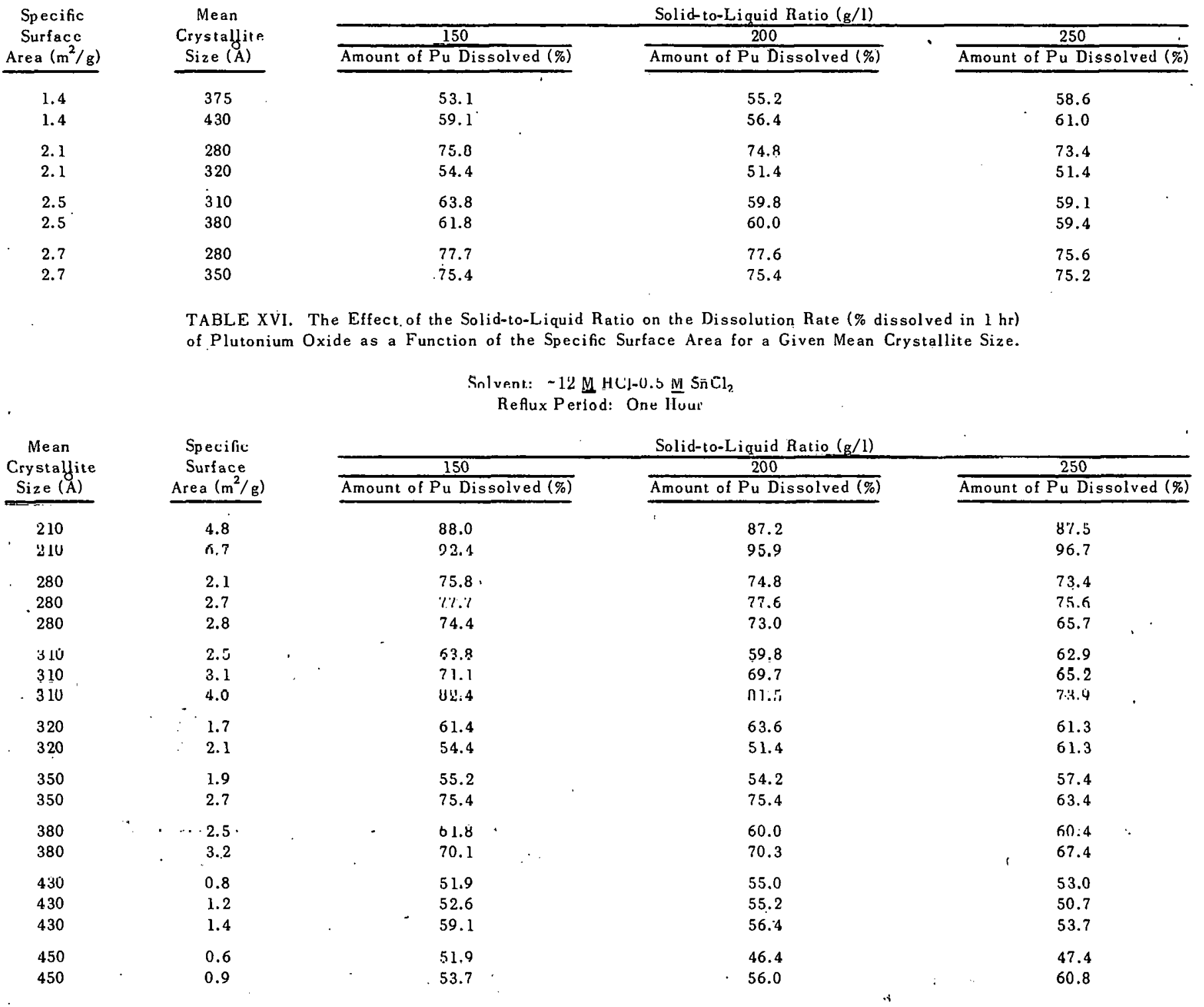




\section{A P P E N D I X}

Tables IA and IIA contain the rate of dissolution results from the oxidc samples. Table IA shows the plutonium concentration of the filtrate from both the nitric acid and hydrochloric acid dissolutions for each solid-to-liquid ratio. Table IIA shows the amount of plutonium dissolved in one hour (\%) from both the nitric acid and hydrochloric acid dissolutions for each solid-to-liquid ratio.

TABLE IA. The Dissolution Rate of Plutonium Oxide.

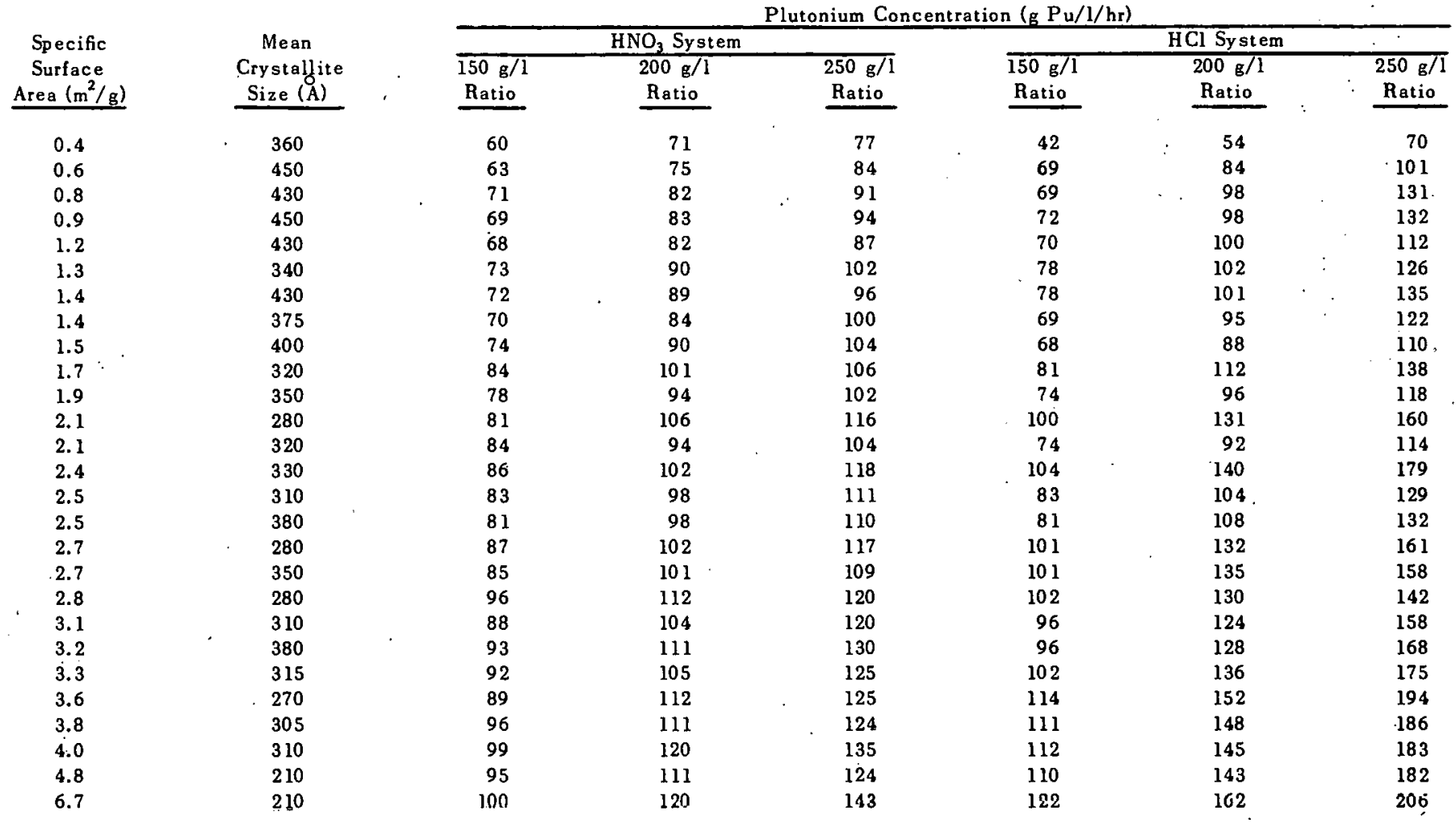


TABLE IIA. The Dissolution Rate of Plutonium Oxide.

\begin{tabular}{cc}
$\begin{array}{c}\text { Specific } \\
\text { Surface } \\
\left.\text { Area } \mathrm{m}^{2} / \mathrm{g}\right)\end{array}$ & $\begin{array}{c}\text { Mean } \\
\text { Crystallite } \\
\text { Size (A) }\end{array}$ \\
\cline { 2 - 3 } 0.4 & 360 \\
0.6 & 450 \\
0.8 & 430 \\
0.9 & 450 \\
1.2 & 430 \\
1.3 & 340 \\
1.4 & 430 \\
1.4 & 375 \\
1.5 & 400 \\
1.7 & 320 \\
1.9 & 350 \\
2.1 & 280 \\
2.1 & 320 \\
2.4 & 330 \\
2.5 & 310 \\
2.5 & 380 \\
2.7 & 280 \\
2.7 & 350 \\
2.8 & 280 \\
3.1 & 310 \\
3.2 & 380 \\
3.3 & 315 \\
3.6 & 270 \\
3.8 & 305 \\
4.0 & 310 \\
4.8 & 210 \\
6.7 & 210 \\
&
\end{tabular}

Amount of Plutonium Dissolved (\% dissolved in $1 \mathrm{hr}$ )

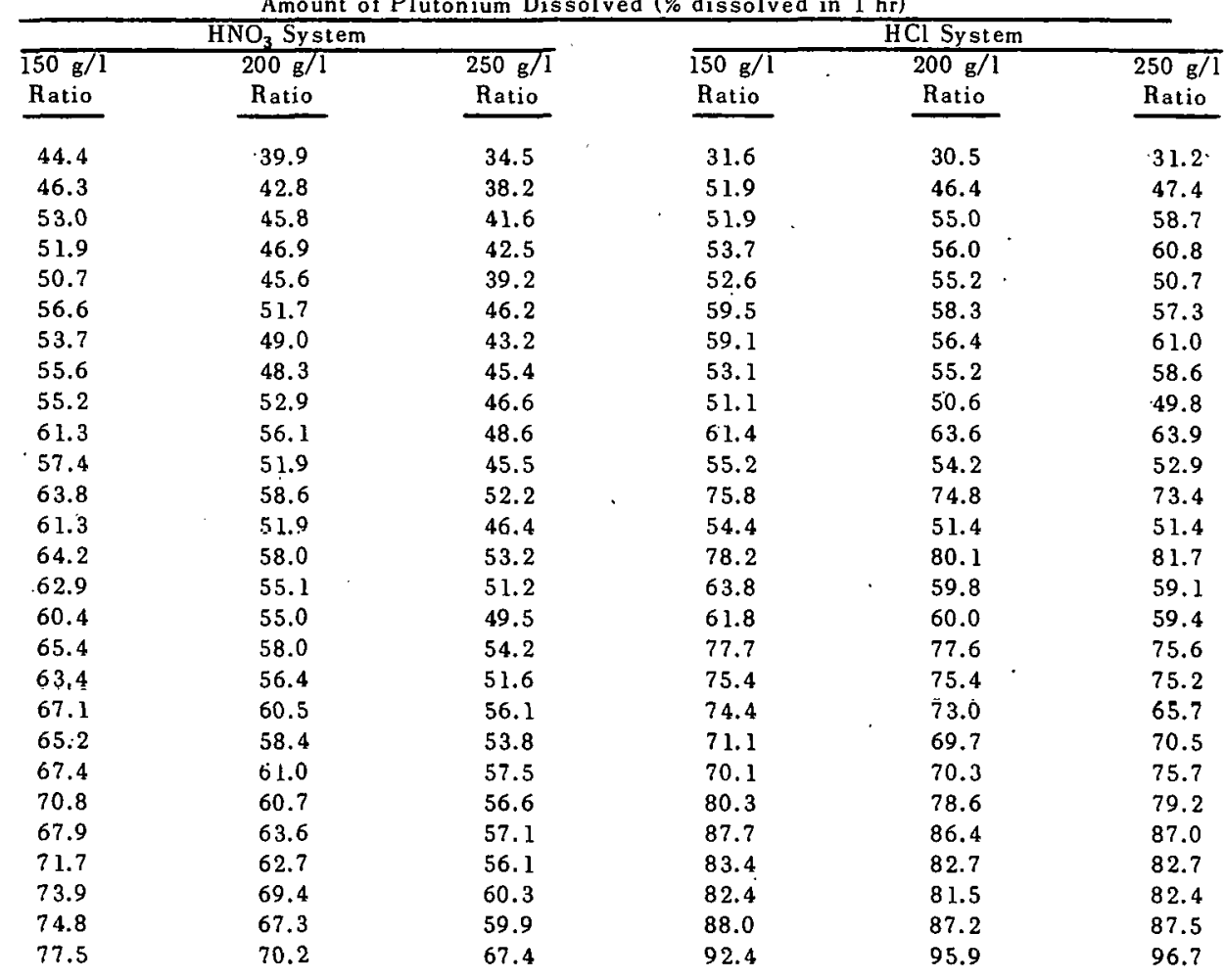

